\title{
Determining Boundary Conditions of Social Influence for Social Networking Site Research
}

\section{Dharshani Chandrasekara}

Monash University, Australia

dharshani.chandrasekara@monash.edu

\section{Darshana Sedera}

Southern Cross University, Australia

\section{Caddie Gao}

Monash University, Australia

\section{Abstract}

Social influence theoretical constructs have been utilized substantially by researchers in Information Systems (IS) to examine interactions in Social Networking Sites (SNSs). However, most of the theoretical constructs of social influence applied in IS studies have been adopted from social influence theories developed before the advent of SNSs. Yet, research on theory development indicates that when applying an existing theory to a novel context, the specification of boundary conditions is crucial. Therefore, in this study, by examining how different social influence constructs have been utilized in past IS studies, we derive five boundary conditions that can be applied to future SNS research. The boundary conditions for SNS research were determined by conducting a literature review with a sample of 65 research papers. Deriving boundary conditions by analyzing recurring patterns in the literature allowed us to generate a foundational knowledge of the use of boundary conditions of social influence for SNS research, which would aid researchers in generating accurate findings. Our findings demonstrate that when applying a theory to a novel context, identification of boundary conditions of a theory would not only contribute to the rigor in research but also support the validation of its practical implications.

Keywords: Social media, Boundary conditions, Theory and philosophy

\section{Introduction}

Along with the advent of Social Networking Sites (SNSs) like Facebook and Twitter, people around the world have been able to reach a new level of social interaction. According to the latest statistics, the global population using SNSs has reached 3.96 billion, with an annual increase of $10.5 \%$ (Chaffey, 2020). Therefore, the effect of social influence is also increasing through SNSs. For example, it is estimated that the average Facebook user has 338 friends (Smith, 2017), while 15\% of Facebook users have more than 500 friends (Smith, 2014). The average Twitter user has 707 followers (MacCarthy, 2016). The high number of individuals interacting with and influencing each other on a daily basis via SNSs shows how the novel context of SNSs has enabled individuals to widen their social circles compared to the low number of members individuals had in their social circles before the advent of SNSs. The effect of such high volumes of influence means that the theoretical boundaries of even wellestablished theories of social influence must be reconsidered. 
The growing SNSs research has revealed that social influence generated by individuals via SNSs, while similar in many aspects to social influence in the pre-SNS era, differs from and challenges the traditional boundaries of social influence (Bagozzi \& Dholakia, 2002; Zhou, 2011). For instance, reach in terms of the number of associates in a social circle (Mangold \& Faulds, 2009) and geographical coverage (Tufekci \& Wilson, 2012) easily exceed the traditional social influence boundaries. Similarly, the frequency of interaction between members in a social circle (Fischer \& Reuber, 2011) also provides potential differences between traditional social influence and social influence facilitated by SNSs.

As such, while the fundamental premise of social influence theories (Zhou, 2011; Zeng et al., 2009) remain relevant, their boundary conditions must be revisited to understand how the changes arising through SNSs could affect a well-established theoretical foundation.

Boundary conditions can simply be defined as the "Who, Where, When" conditions of a theory that "constitute the range of the theory" (Whetten, 1989, p.492). According to Dubin (1969, p. 126) "an experimental situation is different from another by its boundary conditions". When context-specific research is conducted, identifying the boundary conditions that are relevant to that context is the key to conducting the research successfully. Based on this premise, Information Systems (IS) researchers would benefit from identifying the boundary conditions that are applicable for examining social influence in the specific context of SNSs as opposed to social influence that takes place in the physical world, to generate more accurate findings based on the gradual shift that has taken place in human interactions from physical space to digital space (Palekar, Atapattu, Sedera, \& Lokuge, 2018). Therefore, we conducted this study with the objective of assessing the boundary conditions of social influence theoretical perspective, especially in light of the novelty in SNSs. Aligning with this objective, the research question we aim to address through this study is: "What boundary conditions should be considered when engaging in social influence research in the context of SNSs?"

To assess our assertion, we investigated a rigorously selected sample of 65 studies on social influence and SNSs published in top-tier journals. In those selected studies, we made insightful observations about the use of constructs of social influence, theoretical applications, and whether the studies had considered the natural expansions to the underlying foundations that had taken place as a result of SNSs. However, with regard to the theoretical expansion of social influence, we found little evidence that boundary conditions are established, reviewed, or revised explicitly. Therefore, based on our literature review, we derived five boundary conditions necessary for the utilization of the theoretical perspective of social influence in SNSs.

The paper proceeds in the following manner. First, it provides an overview of the theoretical foundations of social influence. Then it investigates the constructs employed in social influence using the literature sample and identifies the most applicable constructs of social influence for SNSs. Next, we show how we derived five boundary conditions of social influence for SNSs and explain the boundary conditions in light of the constructs employed in the social influence studies. Finally, we explain how researchers and practitioners can apply boundary conditions in their SNS research to increase rigor in both theory and practice.

\section{Theoretical Foundations of Social Influence}

Throughout the history of humankind, individuals have attempted to maintain relationships with one another in groups or networks, and the formation and characteristics of such groups 
have always evolved with time (McPherson, Popielarz, \& Drobnic, 1992). In its simplest form, a social network can be defined as "a set of people (or organizations or other social entities) connected by a set of social relationships such as friendship, co-working or information exchange" (Garton, Haythornthwaite, \& Wellman, 1997, para 1). With the advancement of technology, such social networks have been expanded to digital spheres and are visible in the form of SNSs (Boyd \& Ellison, 2007; Chang, Liu, \& Chen, 2014). Even before the proliferation of SNSs, there has been a continuous effort to understand the influence individuals have on one another in such social networks where there are frequent interactions among individuals (Coleman, 1986; Galaskiewicz \& Wasserman, 1993; Kelman, 1958; Latané, 1981).

For the past several decades, studies have delivered various theories and frameworks to better understand social influence (e.g., Bagozzi \& Dholakia, 2002; Kelman, 1958; Kuan, Zhong \& Chau, 2014; Latané, 1981). Especially with the advent and mass proliferation of SNSs, it is evident that social influence is growing and changing (Bagozzi \& Dholakia, 2002; Zeng. et al., 2009). Various disciplines including IS (Palekar et al., 2018), marketing (Dholakia, Bagozzi \& Pearo, 2004), organizational environment (Arvidsson \& Holmström, 2013), political science Tufekci \& Wilson, 2012) and sociology (Golder \& Macy, 2014; Zhang \& Centola, 2019), have examined social influence that occurs as a result of people's interactions in SNSs. Moreover, the social influence generated by individuals in SNSs has been discussed in various sectors, including the automobile industry (Wang, Susarla \& Sambamurthy, 2015), music (Dewan, Ho \& Ramaprasad, 2017), and the film industry (Oh, Roumani \& Nwankpa, 2017). In particular, in the special issue on Recent Advances in Social Media in the Australasian Journal of Information Systems in 2018, many of the published studies (e.g., Grottke, Hacker, \& Durst, 2018; Morgan, Cheong, \& Bedingfield, 2018; Palekar \& Sedera, 2018; Wang, Alahakoon, \& De Silva, 2018; Whiteside, Aleti, Pallant, \& Zeleznikow, 2018) have discussed the importance of social influence generated in SNSs on various aspects of attitudinal and behavioral change (refer to Table 1).

\begin{tabular}{|l|l|}
\hline Study & Aspect discussed in relation to social influence and SNSs \\
\hline Grottke et al. (2018) & $\begin{array}{l}\text { How online interactions influence individuals in terms of generating social } \\
\text { capital. }\end{array}$ \\
\hline Palekar \& Sedera (2018) & How SNS users influence news consumption in social broadcasting networks. \\
\hline Wang et al. (2018) & How SNS users influence the interpretation of media content. \\
\hline Whiteside et al. (2018) & $\begin{array}{l}\text { The means through which interactions with different individuals (who may or } \\
\text { may not belong to an individual's physical social circle) can influence one's } \\
\text { intimate relationships. }\end{array}$ \\
\hline
\end{tabular}

Table 1. The Importance of Social Influence for SNSs (AJIS special issue)

The studies mentioned above emphasize that when examining different phenomenon in the context of SNSs, social influence has always been an area of interest for IS research. This not only proves that examining social influence in SNSs could allow us to understand online interactions better, but it also highlights that we should pay more attention to whether social influence theories which have been established by observing the individual interactions in the physical world could be applied in the same manner for SNSs.

According to Dubin (1969, p. 126), when conducting research, there is a need to identify the "boundary conditions" or "initial conditions" which differentiate one particular study context from another to specify a theoretical model accurately. Considering that there are substantial differences in the way individuals interact in digital spaces such as SNSs and the physical world (Bagozzi \& Dholakia, 2002) it is essential to identify what social influence constructs 
have been discussed in the past in general and what social influence constructs are discussed at present in relation to SNSs. Such an understanding of the way social influence constructs have been adopted in different contexts would allow us to identify whether there are any conditions we should consider in the process of adopting social influence constructs to study various phenomena in the SNSs.

\subsection{Key Theoretical Constructs of Social Influence}

Theoretical foundations of social influence mainly lie in the discipline of social psychology and consist of many different constructs used across several disciplines to understand how social influence can affect individuals. For instance, Deutsch and Gerard (1955) introduced a theory of social influence that consists of two main constructs, namely, normative social influence and informational social influence. Kelman (1958) in his social influence theory, came up with three constructs of social influence, namely, compliance, identification, and internalization to indicate the processes through which people change their attitudes and behaviors based on the influence of others. Introducing social impact theory, Latané (1981) identified another three constructs of social influence, namely, strength, immediacy, and the number of people, which allow us to better understand social influence processes.

Peer pressure (Kandel \& Lazear, 1992), also identified as peer influence, is another commonly adopted social influence construct that examines the role of peers in affecting individual decisions. Further, in the paper "Social influence: Compliance and conformity", Cialdini and Goldstein (2004) discussed two types of social influence namely, compliance and conformity and highlighted that an individual can be influenced based on three types of rewarding goals; goal of accuracy, goal of affiliation and goal of maintaining a positive self-concept. When examining social influence from a theoretical perspective, all these constructs have contributed to our understanding of the different processes of social influence which can influence individuals to form different attitudes and behaviors. Most of these constructs have been adopted by various disciplines to investigate the role of social influence in creating attitudinal and behavioral changes in individuals. Our investigation into how these constructs have been utilized over time in various domains has revealed the breadth of social influence and highlighted the need to identify the social influence constructs that have been widely used in IS.

\subsection{Constructs of Social Influence Used in IS Research}

The role of social influence in digital spheres has been an area of interest for IS for a considerable period (Bagozzi \& Dholakia, 2002; Tsai \& Bagozzi, 2014). IS researchers have employed several constructs of social influence to investigate various phenomena in the digital spheres. Table 2 illustrates the key social influence constructs examined in IS studies chronologically by the year in which the key study related to the social influence construct(s) was published.

This illustration of social influence constructs examined in IS studies indicates that even when digital spaces such as SNSs were selected as the study context, IS studies have used social influence constructs that were developed prior to the advent of SNSs (e.g., Deutsch \& Gerard, 1955; Hovland, Janis, \& Kelley, 1953; Kelman, 1958; Latané, 1981; Nemeth, 1986).

When considering the applicability of each of these constructs to IS, Kuan et al. (2014) utilized informational social influence and normative social influence to understand how purchase decisions in group buying sites can be affected by social influence. In this study, informational influence has been applied in situations where people make decisions based on others' actions 
and judgments, thus treating them as sources of information, and normative influence is applied when people make decisions to comply with others, based on others' preferences or expectations. Further, Kuan et al. (2014) indicated that both informational and normative social influences are contributing to conformity. Kwahk \& Ge (2012) also recognized that SNSs facilitate the promotion of informational influence due to the dissemination of information and knowledge, encouraging SNS users to engage in e-commerce activities more. However, whether or not such theoretical constructs can be applied as they are has not been adequately addressed in these past IS studies.

\begin{tabular}{|l|l|l|}
\hline $\begin{array}{l}\text { Social Influence } \\
\text { construct(s) }\end{array}$ & $\begin{array}{l}\text { Key theory } \\
\text { publication related } \\
\text { to the construct(s) }\end{array}$ & $\begin{array}{l}\text { Examples of IS studies that have examined the social } \\
\text { influence construct(s) }\end{array}$ \\
\hline $\begin{array}{l}\text { Informational social } \\
\text { influence and normative } \\
\text { social influence }\end{array}$ & $\begin{array}{l}\text { (Deutsch \& Gerard, } \\
1955)\end{array}$ & $\begin{array}{l}\text { (Kuan, et al., 2014; K. Zhang, Lee, \& Zhao, 2010; Zhao, } \\
\text { Stylianou, \& Zheng, 2018) }\end{array}$ \\
\hline $\begin{array}{l}\text { Compliance, identification } \\
\text { and internalization }\end{array}$ & (Kelman, 1958) & $\begin{array}{l}\text { (Bagozzi \& Dholakia, 2002; Bagozzi, Dholakia, \& } \\
\text { Mookerjee, 2006; Bagozzi, Dholakia, \& Pearo, 2007; } \\
\text { Cheung, Chiu, \& Lee, 2011; Cheung \& Lee, 2010; Datta, } \\
\text { 2011; Dholakia, Bagozzi, \& Pearo, 2004; Shen, Lee, } \\
\text { Cheung, \& Chen, 2010; Tsai \& Bagozzi, 2014; Wang, } \\
\text { Meister, \& Gray, 2013; Zhou, 2011) }\end{array}$ \\
\hline $\begin{array}{l}\text { Strength, immediacy and } \\
\text { number }\end{array}$ & (Latané, 1981) & $\begin{array}{l}\text { (Chan, Skoumpopoulou, \& Yu, 2018; Kwahk \& Ge, 2012; } \\
\text { Miller \& Brunner, 2008; Mir \& Zaheer, 2012) }\end{array}$ \\
\hline $\begin{array}{l}\text { Peer pressure/peer } \\
\text { influence }\end{array}$ & $\begin{array}{l}\text { (Kandel \& Lazear, } \\
\text { 1992) }\end{array}$ & $\begin{array}{l}\text { (Godinho de Matos, Ferreira, \& Krackhardt, 2014; } \\
\text { Zhang, Pavlou, \& Krishnan, 2018; Zhang, Susarla, \& } \\
\text { Krishnan, 2014) }\end{array}$ \\
\hline
\end{tabular}

Table 2. A Chronological Presentation of Social Influence Constructs

Note: The order of the social influence constructs is presented by the year in which the seminal theory paper related to the constructs was published.

Kelman's social influence theory (1958) and Latané's social impact theory (1981) have also widely been used in IS to analyze individual actions and attitude changes in relation to social influence (refer to Table 2). Notably, the literature analysis conducted through this study indicated these latter two theories as the most applied social influence theories for the context of SNSs. The three social influence constructs of Kelman (1958) were introduced to the academic community in his study on "Compliance, identification, and internalization: Three processes of attitude change". According to this particular study (Kelman, 1958), social influence can be accepted by three different types of processes, namely, compliance, identification and internalization. Herein, compliance refers to the influential capabilities of significant others or powerful people in the influencee's life (Bagozzi and Dholakia, 2002). Identification refers to the process whereby a person acts in a certain way to gain acceptance or a feeling of belongingness to a particular group or an individual (Kelman, 1958). Internalization refers to the process through which a person engages in a particular behavior because the behavior aligns with his/her value system (Kelman, 1958). The foundation for social influence studies in IS, particularly on SNSs, has been mainly laid with the support of Kelman's substantial contribution. A number of IS studies exploring social influence in digital spaces have utilized Kelman's theory on social influence as the basis for their research (refer to Table 2).

When the utilization of social impact theory is considered, Latané (1981, p. 343) defined social impact as "the great variety of changes in physiological states and subjective feelings, motives 
and emotions, cognitions and beliefs, values and behavior, that occur in an individual, human or animal, as a result of the real, implied, or imagined presence or actions of other individuals". In order to influence an individual, he suggested three factors that should be present when an interaction takes place: strength - "the salience, power, importance, or intensity of a given source to the target", immediacy - "closeness in space or time and absence of intervening barriers or filters" and number - "how many people there are" (Latané, 1981, p. 344).

Even though social impact theory was established before the advent of SNSs, several studies have utilized the theory explicitly in explaining the behavior of individuals in digital spaces (Chan, Skoumpopoulou, \& Yu, 2018; Kwahk \& Ge, 2012; Miller \& Brunner, 2008; Mir \& Zaheer, 2012). Miller and Brunner (2008) even redefined the constructs to be appropriate to the online setting. For instance, when relating the construct of immediacy, which is mainly regarding the physical proximity between the source and the target of impact, Miller and Brunner (2008) defined immediacy in the digital environment in terms of user engagement in chatroom dialogues. Concerning the construct of strength, the same study used interpersonal factors such as assertiveness and exaggeration as indicators of strength in the person having an influence online. Such changes to the definitions of social influence constructs further denote the necessity of revisiting the theoretical constructs of social influence in light of SNSs.

Peer influence is another social influence construct that has been widely discussed in IS. This can be defined as the process in which peers or friends play an important role when a specific individual decides to act in a certain way (Godinho de Matos, Ferreira \& Krackhardt, 2014). Bapna and Umyarov (2015) investigated peer influence in SNSs in relation to online purchase decisions. Aral and Walker (2011) also studied the effect of peer influence by experimenting on viral marketing campaigns online. In addition to these social influence constructs that had been discussed even before the advent of SNSs, Dewan et al. (2017) used popularity influence and proximity influence to identify how social influence is generated in SNSs. Herein, the construct of popularity influence is explained in relation to the concept of word-of-mouth and observational learning through which consumers are influenced by their interactions with others. Proximity influence is defined in the same study as influence generated by close social circles in the social network.

In summary, in reviewing IS studies that have examined social influence, we identified that social influence studies in IS mainly employ the constructs ${ }^{1}$ of compliance, identification, internalization, peer influence, informational social influence, normative social influence, strength, immediacy, and number of people as the key variables in analyzing the behaviors of people (e.g. Bagozzi \& Dholakia, 2002; Kuan et al., 2014; Kwahk \& Ge, 2012; Mir \& Zaheer, 1970; Sedera, Lokuge, Atapattu, \& Gretzel, 2017; Zhang, Pavlou, \& Krishnan, 2018). While these studies have contributed to the extension of knowledge greatly, one crucial factor that has not been studied adequately is whether these constructs can be applied in the same way to SNSs considering they were developed prior to the advent of SNSs. In order to investigate this matter further, we conducted a literature review to analyze the use of the social influence constructs in past social influence and SNS research and to examine what types of boundary conditions should be specified when social influence constructs are applied to SNSs.

\footnotetext{
${ }^{1}$ The logical derivation of the most applied social influence constructs in IS discussed in detail in Section 3.
} 


\section{Methodology and Analysis}

\subsection{Overview of the Literature Sample}

\begin{tabular}{|c|c|}
\hline Steps & Results/Comments \\
\hline $\begin{array}{l}\text { 1. Identification of suitable } \\
\text { publishing outlets to conduct } \\
\text { the literature search. }\end{array}$ & $\begin{array}{l}\text { Selecting the Basket-of-08 IS journals: Management Information Systems } \\
\text { Quarterly, European Journal of Information Systems, Information Systems } \\
\text { Research, Information Systems Journal, Journal of Information Technology, } \\
\text { Journal of Strategic Information Systems, Journal of Management Information } \\
\text { Systems, Journal of the Association for Information Systems }\end{array}$ \\
\hline $\begin{array}{l}\text { 2. Identification of } \\
\text { appropriate } \\
\text { keywords/strings for the } \\
\text { literature search. }\end{array}$ & $\begin{array}{l}\text { Keywords: "social influence", "influence", "social influence and social media", } \\
\text { "social influence and social networks", "social media", "social impact", "social } \\
\text { impact and social media", "impact", "social interaction and social media" }\end{array}$ \\
\hline $\begin{array}{l}\text { 3. Selecting the time period } \\
\text { for the literature search. }\end{array}$ & $\begin{array}{l}2008 \text { to } 2018 \text { was selected as the appropriate period for the initial set of research } \\
\text { papers relevant to the objectives of the research. }\end{array}$ \\
\hline $\begin{array}{l}\text { 4. Carrying out the } \\
\text { Literature Search using the } \\
\text { keywords and downloading } \\
\text { the relevant papers. }\end{array}$ & $\begin{array}{l}\text { Inclusion criteria: (i) Papers with titles and abstracts with a focus on either } \\
\text { human interactions in digital spaces or social influence in the context of } \\
\text { Information Technology or IS, (ii) Papers using both qualitative and qualitative } \\
\text { methods, and literature reviews. } \\
\text { Downloaded } 193 \text { papers in total. }\end{array}$ \\
\hline $\begin{array}{l}\text { 5. Reviewing full content of } \\
\text { the downloaded papers to } \\
\text { identify the most relevant } \\
\text { papers for the study. }\end{array}$ & $\begin{array}{l}\text { Exclusion criteria: Papers that did not discuss or examine the occurrence of } \\
\text { different types of social influence. } \\
\text { Finalized } 13 \text { papers relevant to the research from the initial search. }\end{array}$ \\
\hline $\begin{array}{l}\text { 6. Engaging in backward } \\
\text { search (reviewing the } \\
\text { reference lists of the } 13 \\
\text { papers) and forward search } \\
\text { (reviewing the studies that } \\
\text { have cited the } 13 \text { papers } \\
\text { using Google Scholar } \\
\text { database) to identify more } \\
\text { suitable papers for the } \\
\text { literature sample. }\end{array}$ & $\begin{array}{l}\text { Inclusion criteria: (i) Seminal studies on social influence, (ii) Papers discussing } \\
\text { either human interactions in digital spaces or social influence in the context of } \\
\text { Information Technology or IS. } \\
45 \text { papers were added to the literature sample. }\end{array}$ \\
\hline $\begin{array}{l}\text { 7. Adding PlumX highly } \\
\text { cited SNS research that was } \\
\text { not identified in the previous } \\
\text { stages to the literature } \\
\text { sample } \\
\text { Note: The PlumX metrics } \\
\text { "gathers and brings together } \\
\text { appropriate research metrics for } \\
\text { all types of scholarly research } \\
\text { output" (PlumX Metrics - } \\
\text { Plum Analytics, n.d.) }\end{array}$ & $\begin{array}{l}\text { Inclusion criteria: Papers discussing either human interactions in SNSs or social } \\
\text { influence in SNSs. } \\
7 \text { papers were added to the literature sample. }\end{array}$ \\
\hline $\begin{array}{l}\text { Total no. of papers selected } \\
\text { for the literature sample }\end{array}$ & $13+45+7=65$ \\
\hline
\end{tabular}

Table 3. The Methodology for Selecting Papers Relevant for the Literature Review

The objectives of the literature analysis were to: (i) develop an understanding of the importance of revisiting social influence theory for SNSs; (ii) identify the social influence constructs applicable for SNSs, and (iii) derive boundary conditions for SNS research as necessary. The literature analysis was deemed to be the most appropriate approach for the 
study as we established that even though different theoretical constructs of social influence have been widely utilized in the domain of IS, (Bagozzi et al., 2006; Bagozzi \& Dholakia, 2002; Eckhardt, Laumer, \& Weitzel, 2009; Kuan et al., 2014; Sedera et al., 2017; Tsai \& Bagozzi, 2014; Vannoy \& Palvia, 2010), to date, a comprehensive literature analysis on this topic has not been conducted. In the meantime, a literature analysis would lay a strong foundation for future research employing social influence constructs to examine social interactions in SNSs. Notably, IS as a discipline has emphasized the necessity of producing literature reviews to strengthen the foundation of IS in terms of both theory development and progression as a discipline (Webster \& Watson, 2002). The methodology for selecting literature is outlined in Table 3.

\subsection{Analysis}

Once the literature sample of 65 studies was assembled, we distilled the constructs of measurement. We first identified papers in the sample that discussed theoretical constructs of social influence in relation to human interactions and attitudinal/behavioral change. We then narrowed down the most common constructs of social influence emphasized in the studies. In papers where constructs of social influence were not explicitly discussed, we assigned the most appropriate constructs for the study based on the discussions presented by authors regarding the type of influence taking place in their study. Table 4 includes the study ${ }^{2}$ and the corresponding constructs employed, denoted in columns ' $\mathrm{A}$ ' to ' $\mathrm{I}$ '. The constructs denoted in Table 4 include three from Kelman's social influence theory (1958); (A) compliance, (B) identification, (C) internalization, other commonly used social influence constructs in IS; (D) peer influence, (E) informational influence, and (F) normative influence, and three constructs from Latané's social impact theory (1981); (G) immediacy, (H) strength, and (I) number of people.

The initial mapping of the constructs was completed by one author and verified by the other two authors. A comparison of the individual classifications revealed average inter-coder reliability exceeding $80 \%{ }^{3}$. Then we added binary values to the Table: ' $Y^{\prime}$ if the study explicitly or implicitly discussed a particular construct and ' $\mathrm{N}$ ' if the study did not discuss a particular construct at all. The Table was designed following the "concept matrix augmented with units of analysis" structure recommended by Webster \& Watson (2002, p. xvii) in the MIS Quarterly guest editorial titled 'Analyzing the Past to Prepare for the Future: Writing a Literature Review'.

Table 4 also allowed us to identify some common themes along which the analysis can be carried out. According to Webster and Watson (2002, p. xvii) "isolating concepts by units of analysis should result in a crisp review because it is easier to detect when you let a concept stray outside the scope of its domain". Hence, using Table 4, we identified the most used constructs of social influence, overlaps between the social influence constructs, and the evolution of constructs. Finally, once the literature sample was analyzed under these themes, we derived the boundary conditions of social influence that could be established for SNS research.

\footnotetext{
2 The complete list of references for Table 4 can be found in Appendix A.

3 Krippendorff (1980) recommends inter-coder reliability of at least $70 \%$.
} 


\begin{tabular}{|c|c|c|c|c|c|c|c|c|c|}
\hline Study & A & B & C & D & E & F & G & H & I \\
\hline (Kelman, 1958) & $\mathrm{Y}$ & $\mathrm{Y}$ & Y & $\mathrm{N}$ & Y & Y & $\mathrm{N}$ & $\mathrm{Y}$ & $\mathrm{N}$ \\
\hline (Latané, 1981) & Y & $\mathrm{N}$ & $\mathrm{N}$ & $\mathrm{N}$ & $\mathrm{N}$ & $\mathrm{Y}$ & $\mathrm{Y}$ & Y & Y \\
\hline (Nowak et al., 1990) & $\mathrm{Y}$ & $\mathrm{N}$ & $\mathrm{N}$ & $\mathrm{N}$ & $\mathrm{Y}$ & $\mathrm{Y}$ & $\mathrm{Y}$ & $\mathrm{Y}$ & $\mathrm{Y}$ \\
\hline (Latané et al., 1995) & $\mathrm{Y}$ & $\mathrm{N}$ & $\mathrm{N}$ & $\mathrm{N}$ & $\mathrm{N}$ & $\mathrm{Y}$ & $\mathrm{Y}$ & $\mathrm{Y}$ & $\mathrm{Y}$ \\
\hline (Latané, 1996) & $\mathrm{Y}$ & $\mathrm{Y}$ & $\mathrm{N}$ & $\mathrm{N}$ & $\mathrm{N}$ & $\mathrm{Y}$ & $\mathrm{Y}$ & $\mathrm{Y}$ & Y \\
\hline * (Latané and Bourgeois, 1996) & $\mathrm{N}$ & $\mathrm{N}$ & $\mathrm{N}$ & $\mathrm{N}$ & $\mathrm{N}$ & $\mathrm{N}$ & Y & $\mathrm{Y}$ & Y \\
\hline (Venkatesh and Davis, 2000) & $\mathrm{Y}$ & $\mathrm{Y}$ & $\mathrm{Y}$ & $\mathrm{N}$ & $\mathrm{Y}$ & $\mathrm{Y}$ & $\mathrm{N}$ & $\mathrm{Y}$ & $\mathrm{N}$ \\
\hline *(Bagozzi and Dholakia, 2002) & $\mathrm{Y}$ & $\mathrm{Y}$ & $\mathrm{Y}$ & $\mathrm{N}$ & Y & $\mathrm{Y}$ & $\mathrm{N}$ & $\mathrm{N}$ & $\mathrm{Y}$ \\
\hline (Dholakia and Talukdar, 2004) & $\mathrm{Y}$ & $\mathrm{N}$ & $\mathrm{N}$ & $\mathrm{N}$ & Y & $\mathrm{Y}$ & $\mathrm{N}$ & $\mathrm{Y}$ & $\mathrm{N}$ \\
\hline *(Dholakia et al., 2004) & $\mathrm{Y}$ & $\mathrm{Y}$ & $\mathrm{Y}$ & $\mathrm{N}$ & $\mathrm{Y}$ & $\mathrm{Y}$ & $\mathrm{N}$ & $\mathrm{N}$ & $\mathrm{N}$ \\
\hline (Algesheimer et al., 2005) & $\mathrm{Y}$ & $\mathrm{Y}$ & $\mathrm{N}$ & $\mathrm{N}$ & $\mathrm{Y}$ & $\mathrm{Y}$ & $\mathrm{N}$ & $\mathrm{Y}$ & $\mathrm{Y}$ \\
\hline (Lu et al., 2005) & $\mathrm{Y}$ & $\mathrm{Y}$ & $\mathrm{Y}$ & $\mathrm{N}$ & $\mathrm{Y}$ & $\mathrm{Y}$ & $\mathrm{N}$ & $\mathrm{Y}$ & $\mathrm{N}$ \\
\hline (Gallivan et al., 2005) & $\mathrm{Y}$ & $\mathrm{N}$ & Y & $\mathrm{Y}$ & Y & $\mathrm{Y}$ & $\mathrm{N}$ & $\mathrm{Y}$ & $\mathrm{N}$ \\
\hline (Lee et al., 2006) & $\mathrm{Y}$ & $\mathrm{N}$ & $\mathrm{Y}$ & $\mathrm{N}$ & $\mathrm{N}$ & $\mathrm{Y}$ & $\mathrm{N}$ & $\mathrm{N}$ & $\mathrm{N}$ \\
\hline *(Song and Kim, 2006) & $\mathrm{Y}$ & $\mathrm{Y}$ & $\mathrm{N}$ & $\mathrm{Y}$ & $\mathrm{Y}$ & $\mathrm{Y}$ & $\mathrm{N}$ & $\mathrm{Y}$ & $\mathrm{N}$ \\
\hline (Li et al., 2006) & Y & $\mathrm{N}$ & Y & $\mathrm{N}$ & $\mathrm{N}$ & $\mathrm{Y}$ & $\mathrm{N}$ & $\mathrm{N}$ & $\mathrm{N}$ \\
\hline *(Bagozzi et al., 2006) & $\mathrm{Y}$ & $\mathrm{Y}$ & $\mathrm{Y}$ & $\mathrm{N}$ & $\mathrm{N}$ & Y & $\mathrm{N}$ & $\mathrm{Y}$ & $\mathrm{N}$ \\
\hline *(Bagozzi et al., 2007) & $\mathrm{Y}$ & $\mathrm{Y}$ & $\mathrm{Y}$ & $\mathrm{N}$ & $\mathrm{N}$ & $\mathrm{Y}$ & $\mathrm{Y}$ & $\mathrm{Y}$ & $\mathrm{N}$ \\
\hline *(Miller and Brunner, 2008) & $\mathrm{Y}$ & $\mathrm{N}$ & $\mathrm{N}$ & $\mathrm{Y}$ & $\mathrm{N}$ & $\mathrm{Y}$ & $\mathrm{Y}$ & $\mathrm{Y}$ & $\mathrm{Y}$ \\
\hline${ }^{* *(W a l t h e r ~ e t ~ a l ., ~ 2008) ~}$ & $\mathrm{~N}$ & $\mathrm{~N}$ & $\mathrm{~N}$ & $\mathrm{Y}$ & $\mathrm{N}$ & $\mathrm{N}$ & $\mathrm{Y}$ & $\mathrm{N}$ & $\mathrm{N}$ \\
\hline (Eckhardt et al., 2009) & Y & $\mathrm{N}$ & $\mathrm{N}$ & $\mathrm{Y}$ & Y & $\mathrm{Y}$ & $\mathrm{N}$ & $\mathrm{Y}$ & $\mathrm{N}$ \\
\hline (Yang et al., 2009) & $\mathrm{Y}$ & $\mathrm{Y}$ & Y & $\mathrm{N}$ & Y & $\mathrm{Y}$ & $\mathrm{Y}$ & Y & $\mathrm{Y}$ \\
\hline **(Mangold and Faulds, 2009) & $\mathrm{N}$ & $\mathrm{N}$ & $\mathrm{N}$ & $\mathrm{N}$ & $\mathrm{Y}$ & $\mathrm{N}$ & $\mathrm{N}$ & $\mathrm{N}$ & $\mathrm{N}$ \\
\hline **(Pempek et al., 2009) & $\mathrm{N}$ & $\mathrm{N}$ & $\mathrm{N}$ & $\mathrm{Y}$ & $\mathrm{N}$ & $\mathrm{Y}$ & $\mathrm{N}$ & $\mathrm{N}$ & $\mathrm{N}$ \\
\hline (Kulviwat et al., 2009) & Y & $\mathrm{Y}$ & Y & $\mathrm{N}$ & Y & $\mathrm{Y}$ & $\mathrm{N}$ & Y & $\mathrm{N}$ \\
\hline$* *$ (Zeng et al., 2009) & $\mathrm{N}$ & $\mathrm{Y}$ & $\mathrm{Y}$ & $\mathrm{N}$ & $\mathrm{N}$ & $\mathrm{Y}$ & $\mathrm{N}$ & $\mathrm{N}$ & $\mathrm{N}$ \\
\hline **(Kaplan and Haenlein, 2010) & $\mathrm{Y}$ & $\mathrm{Y}$ & $\mathrm{N}$ & $\mathrm{N}$ & $\mathrm{N}$ & $\mathrm{Y}$ & $\mathrm{Y}$ & $\mathrm{N}$ & $\mathrm{N}$ \\
\hline *(Shen et al., 2010) & $\mathrm{Y}$ & $\mathrm{Y}$ & $\mathrm{Y}$ & $\mathrm{Y}$ & $\mathrm{N}$ & $\mathrm{Y}$ & $\mathrm{N}$ & $\mathrm{Y}$ & $\mathrm{N}$ \\
\hline *(Posey et al., 2010) & $\mathrm{N}$ & $\mathrm{Y}$ & $\mathrm{N}$ & $\mathrm{N}$ & $\mathrm{Y}$ & $\mathrm{Y}$ & $\mathrm{N}$ & $\mathrm{N}$ & $\mathrm{N}$ \\
\hline *(Huffaker, 2010) & $\mathrm{Y}$ & $\mathrm{N}$ & $\mathrm{N}$ & $\mathrm{N}$ & $\mathrm{Y}$ & $\mathrm{Y}$ & $\mathrm{Y}$ & $\mathrm{Y}$ & $\mathrm{Y}$ \\
\hline (Glass and Li, 2010) & $\mathrm{Y}$ & $\mathrm{N}$ & $\mathrm{N}$ & $\mathrm{Y}$ & $\mathrm{N}$ & $\mathrm{Y}$ & $\mathrm{N}$ & $\mathrm{Y}$ & $\mathrm{Y}$ \\
\hline (Vannoy and Palvia, 2010) & $\mathrm{Y}$ & $\mathrm{N}$ & $\mathrm{N}$ & $\mathrm{N}$ & $\mathrm{N}$ & $\mathrm{Y}$ & $\mathrm{N}$ & $\mathrm{Y}$ & $\mathrm{N}$ \\
\hline${ }^{* *}($ Cheung and Lee, 2010) & $\mathrm{Y}$ & $\mathrm{Y}$ & $\mathrm{Y}$ & $\mathrm{N}$ & $\mathrm{N}$ & $\mathrm{Y}$ & $\mathrm{N}$ & $\mathrm{Y}$ & $\mathrm{Y}$ \\
\hline **(Zhou, 2011) & $\mathrm{Y}$ & $\mathrm{Y}$ & $\mathrm{Y}$ & $\mathrm{N}$ & $\mathrm{N}$ & $\mathrm{Y}$ & $\mathrm{N}$ & $\mathrm{Y}$ & $\mathrm{N}$ \\
\hline (Datta, 2011) & $\mathrm{Y}$ & $\mathrm{Y}$ & $\mathrm{Y}$ & $\mathrm{N}$ & $\mathrm{N}$ & $\mathrm{Y}$ & $\mathrm{N}$ & $\mathrm{Y}$ & $\mathrm{N}$ \\
\hline (Shen et al., 2011) & $\mathrm{Y}$ & $\mathrm{Y}$ & $\mathrm{Y}$ & $\mathrm{N}$ & $\mathrm{N}$ & $\mathrm{Y}$ & $\mathrm{N}$ & $\mathrm{Y}$ & $\mathrm{N}$ \\
\hline **(Cheung et al., 2011) & $\mathrm{Y}$ & $\mathrm{Y}$ & $\mathrm{Y}$ & $\mathrm{N}$ & $\mathrm{Y}$ & $\mathrm{Y}$ & $\mathrm{N}$ & $\mathrm{Y}$ & $\mathrm{N}$ \\
\hline **(Kietzmann et al., 2011) & $\mathrm{N}$ & $\mathrm{N}$ & $\mathrm{N}$ & $\mathrm{Y}$ & $\mathrm{N}$ & $\mathrm{N}$ & $\mathrm{N}$ & Y & Y \\
\hline
\end{tabular}




\begin{tabular}{|c|c|c|c|c|c|c|c|c|c|}
\hline **(Hanna et al., 2011) & $\mathrm{N}$ & $\mathrm{N}$ & $\mathrm{N}$ & $\mathrm{Y}$ & $\mathrm{Y}$ & $\mathrm{N}$ & $\mathrm{N}$ & $\mathrm{N}$ & $\mathrm{N}$ \\
\hline **(Fischer and Reuber, 2011) & $\mathrm{N}$ & $\mathrm{N}$ & $\mathrm{N}$ & $\mathrm{N}$ & $\mathrm{N}$ & $\mathrm{Y}$ & $\mathrm{N}$ & $\mathrm{N}$ & $\mathrm{N}$ \\
\hline **(Mir and Zaheer, 2012) & $\mathrm{N}$ & $\mathrm{N}$ & $\mathrm{N}$ & $\mathrm{N}$ & $\mathrm{Y}$ & $\mathrm{N}$ & Y & $\mathrm{Y}$ & $\mathrm{Y}$ \\
\hline **(Kwahk and Ge, 2012) & $\mathrm{Y}$ & $\mathrm{Y}$ & $\mathrm{N}$ & $\mathrm{N}$ & $\mathrm{Y}$ & $\mathrm{Y}$ & Y & Y & Y \\
\hline **(Tufekci and Wilson, 2012) & $\mathrm{N}$ & $\mathrm{N}$ & $\mathrm{N}$ & $\mathrm{N}$ & $\mathrm{Y}$ & $\mathrm{N}$ & $\mathrm{N}$ & $\mathrm{Y}$ & $\mathrm{N}$ \\
\hline **(Lipsman et al., 2012) & $\mathrm{N}$ & $\mathrm{N}$ & $\mathrm{N}$ & Y & $\mathrm{N}$ & $\mathrm{N}$ & Y & $\mathrm{N}$ & Y \\
\hline **(Gensler et al., 2013) & $\mathrm{N}$ & $\mathrm{N}$ & $\mathrm{N}$ & $\mathrm{Y}$ & $\mathrm{Y}$ & $\mathrm{N}$ & $\mathrm{N}$ & Y & Y \\
\hline (Singh and Phelps, 2013) & $\mathrm{Y}$ & $\mathrm{N}$ & $\mathrm{N}$ & $\mathrm{Y}$ & $\mathrm{Y}$ & $\mathrm{Y}$ & $\mathrm{Y}$ & $\mathrm{Y}$ & $\mathrm{N}$ \\
\hline **(Hildebrand et al., 2013) & $\mathrm{Y}$ & Y & $\mathrm{Y}$ & $\mathrm{N}$ & $\mathrm{Y}$ & $\mathrm{Y}$ & $\mathrm{N}$ & $\mathrm{Y}$ & $\mathrm{N}$ \\
\hline (Wang et al., 2013) & Y & $\mathrm{Y}$ & Y & Y & $\mathrm{Y}$ & $\mathrm{Y}$ & Y & $\mathrm{Y}$ & $\mathrm{N}$ \\
\hline *(Tsai and Bagozzi, 2014) & Y & $\mathrm{Y}$ & Y & $\mathrm{N}$ & $\mathrm{Y}$ & $\mathrm{Y}$ & $\mathrm{N}$ & $\mathrm{Y}$ & Y \\
\hline *(Kuan et al., 2014) & $\mathrm{Y}$ & $\mathrm{Y}$ & $\mathrm{N}$ & $\mathrm{Y}$ & $\mathrm{Y}$ & $\mathrm{Y}$ & $\mathrm{N}$ & $\mathrm{Y}$ & $\mathrm{Y}$ \\
\hline **(Zhang et al., 2014) & $\mathrm{N}$ & $\mathrm{N}$ & $\mathrm{N}$ & $\mathrm{Y}$ & $\mathrm{N}$ & $\mathrm{N}$ & $\mathrm{Y}$ & $\mathrm{N}$ & $\mathrm{Y}$ \\
\hline (Godinho de Matos et al., 2014) & $\mathrm{N}$ & Y & $\mathrm{N}$ & Y & $\mathrm{N}$ & $\mathrm{Y}$ & $\mathrm{N}$ & $\mathrm{N}$ & Y \\
\hline **(Hu et al., 2015) & $\mathrm{N}$ & $\mathrm{N}$ & $\mathrm{N}$ & $\mathrm{N}$ & $\mathrm{N}$ & $\mathrm{N}$ & $\mathrm{N}$ & $\mathrm{N}$ & $\mathrm{N}$ \\
\hline **(Wang et al., 2015) & $\mathrm{N}$ & $\mathrm{N}$ & $\mathrm{N}$ & $\mathrm{N}$ & $\mathrm{N}$ & $\mathrm{N}$ & $\mathrm{N}$ & $\mathrm{N}$ & $\mathrm{N}$ \\
\hline **(Matook et al., 2015) & $\mathrm{Y}$ & $\mathrm{Y}$ & $\mathrm{N}$ & $\mathrm{Y}$ & $\mathrm{N}$ & $\mathrm{Y}$ & $\mathrm{N}$ & $\mathrm{Y}$ & $\mathrm{N}$ \\
\hline **(Tussyadiah et al., 2015) & $\mathrm{N}$ & $\mathrm{Y}$ & Y & Y & $\mathrm{Y}$ & $\mathrm{Y}$ & $\mathrm{N}$ & Y & $\mathrm{N}$ \\
\hline **(Oh et al., 2017) & $\mathrm{N}$ & $\mathrm{N}$ & $\mathrm{N}$ & $\mathrm{N}$ & $\mathrm{Y}$ & $\mathrm{N}$ & $\mathrm{N}$ & $\mathrm{N}$ & $\mathrm{N}$ \\
\hline **(Sedera et al., 2017) & $\mathrm{Y}$ & $\mathrm{Y}$ & Y & $\mathrm{Y}$ & $\mathrm{Y}$ & $\mathrm{Y}$ & $\mathrm{N}$ & $\mathrm{Y}$ & $\mathrm{Y}$ \\
\hline **(Thomaz et al., 2017) & $\mathrm{N}$ & $\mathrm{N}$ & $\mathrm{N}$ & $\mathrm{N}$ & $\mathrm{N}$ & $\mathrm{N}$ & $\mathrm{N}$ & $\mathrm{N}$ & $\mathrm{N}$ \\
\hline **(James et al., 2017) & $\mathrm{N}$ & $\mathrm{N}$ & $\mathrm{N}$ & Y & $\mathrm{N}$ & $\mathrm{N}$ & $\mathrm{N}$ & $\mathrm{N}$ & $\mathrm{N}$ \\
\hline *(Liao et al., 2017) & $\mathrm{N}$ & $\mathrm{N}$ & $\mathrm{N}$ & $\mathrm{N}$ & $\mathrm{N}$ & $\mathrm{N}$ & $\mathrm{N}$ & $\mathrm{N}$ & $\mathrm{N}$ \\
\hline **(Rueda et al., 2017) & $\mathrm{Y}$ & $\mathrm{Y}$ & $\mathrm{N}$ & $\mathrm{Y}$ & $\mathrm{N}$ & $\mathrm{Y}$ & $\mathrm{N}$ & $\mathrm{Y}$ & $\mathrm{N}$ \\
\hline **(Brandt et al., 2017) & $\mathrm{N}$ & $\mathrm{N}$ & $\mathrm{N}$ & $\mathrm{N}$ & $\mathrm{N}$ & $\mathrm{N}$ & $\mathrm{N}$ & $\mathrm{N}$ & $\mathrm{N}$ \\
\hline **(Dewan et al., 2017) & $\mathrm{N}$ & $\mathrm{N}$ & $\mathrm{N}$ & Y & $\mathrm{N}$ & $\mathrm{N}$ & $\mathrm{N}$ & $\mathrm{N}$ & Y \\
\hline (Zhang et al., 2018) & $\mathrm{N}$ & $\mathrm{N}$ & $\mathrm{N}$ & $\mathrm{Y}$ & $\mathrm{N}$ & $\mathrm{N}$ & $\mathrm{N}$ & $\mathrm{N}$ & Y \\
\hline
\end{tabular}

Table 4. Literature Synthesis

Note: A - Compliance, B - Identification, C - Internalization, D - Peer Influence, E-Informational Social Influence, F-Normative Social Influence, G - Immediacy, H-Strength, I-Number of People

\subsubsection{Most Used Constructs}

Considering that the number of SNS users had risen significantly by 2007 (Kaplan \& Haenlein, 2010), the period before 2008 was set as the pre-SNS era and 2008 onwards as the SNS era for the purpose of identifying and comparing the use of social influence constructs in the literature. According to the analysis, the most discussed social influence constructs before 2008 were compliance $(94 \%)$, normative social influence $(94 \%)$, and strength $(78 \%)$. When comparing these constructs with the most used social influence constructs after the advent of SNSs (2008 onwards), it was evident that normative social influence (62\%) was the most discussed construct, followed by strength (57\%) and compliance (49\%). Even though compliance remained among the top three constructs discussed, its emphasis in IS studies decreased after the advent of SNSs. 
This finding adheres to the argument in the study by Zhou (2011), which indicated that constructs such as compliance cannot be applied to SNSs since individuals have the ability to make voluntary choices in SNSs.

\subsubsection{Overlaps between Constructs}

The analysis highlighted that there is a possible (and perhaps unintentional) overlap between the constructs of Kelman's social influence theory (1958) and Latané's social impact theory (1981). For instance, Latané (1981, p. 344), defines strength in social impact as "the salience, power, importance, or intensity of a given source to the target". Kelman (1958) refers to compliance as a process due to which an individual would behave in a particular way in order to receive rewards or approval from a person or a group, or due to the fear of being rejected (Bagozzi \& Lee, 2002; Datta, 2011; Shen et al., 2010; Zhou, 2011). Hence, when an individual is influenced due to compliance, it is because the influencer is either an important or a powerful person in his/her life. The literature analysis indicated compliance (49\%) and strength (57\%) as two of the most discussed constructs in the SNS era. Due to the similar nature of these constructs, when a study explicitly discusses one construct, it is possible to discuss the other construct implicitly, and that could be one reason why both constructs appear in the top three social influence constructs in IS studies.

Further, Kelman (1958) refers to identification as a process due to which a person is influenced to either establish or continue a successful relationship with another person or a group (Cheung et al., 2011; Wang et al., 2013). Kelman (1958, p.53), adds that for these two processes to be successful, the determinants of influence, namely "the relative importance of the anticipated effect" and "the relative power of the influencing agent" should be considered. While strength in social impact research has been discussed in the perspective of the source of impact, compliance and identification have been discussed in the perspective of the target. However, power, salience, intensity, and importance can be considered as attributes that should be possessed by the influencer under compliance and identification to influence another person. Therefore, such constructs of social impact should be best perceived as moderating constructs that affect the social influence processes. Further, these overlaps may influence the boundary conditions discussed later on in this study.

When considering the social influence constructs in terms of definitions, informational social influence showed similarity to the construct internalization (Bagozzi \& Lee, 2002; Venkatesh \& Davis, 2000), and peer influence showed similarity to the construct identification. It was also observed that the normative social influence construct provided a high-level observation of the overall social influence rather than providing a specific construct to measure social influence. This could be one reason why normative social influence was one of the most discussed constructs in both pre-SNS era (94\%) and SNS era (62\%) studies. Thus, considering all the observed constructs of social influence in the literature sample, the constructs proposed in Kelman's social influence theory (1958): compliance, identification, and internalization were identified as the more explicit and dominating constructs of social influence.

\subsubsection{The Evolution of Constructs}

The literature sample in Table 4 is chronologically ordered. While it was expected that the number of studies employing social influence would increase over time (with the advent and proliferation of SNSs), in reality, the number of such studies is plateauing. The comparison between the periods in which the studies were published (i.e., pre-SNS era and SNS era) highlighted that there are no substantial differences in the application of social influence 
constructs in the two different contexts. The lack of acknowledgment of the novel context could be one of the reasons why the same social influence constructs (while there are minor differences in the order they are discussed) have been highlighted in IS studies.

However, when considering the least discussed constructs, it was evident that peer influence $(11 \%)$, which was one of the least discussed constructs in the pre-SNS era, was replaced by internalization (30\%) in the SNS era. The high number of members in an individual's social circle in the SNS era could be one reason why peer influence has been discussed more in the studies since 2008. Most interestingly, both immediacy and number of people remained among the least discussed constructs in both the pre-SNS and SNS eras.

The complexity in considering a variety of social influence constructs in both the pre-SNS and SNS eras emphasizes the necessity of investigating boundary conditions for SNS by revisiting social influence theory and deriving the most appropriate constructs to examine attitudinal and behavioral changes in individuals. For instance, if the increase in interactions facilitated by the high number of people available in SNS (Smith, 2017) is considered, social influence constructs such as the number of people, and immediacy would become more important in the SNS era compared to the pre-SNS era. Yet, such constructs still receive limited attention in SNS studies since the social influence constructs that were considered important in the pre-SNS era are being applied to the SNS era without acknowledging these contextual differences. Even though several new constructs, such as popularity influence and proximity influence (Dewan et al., 2017) were introduced in IS studies to capture the social influence generated by people in SNSs, the emphasis placed on these constructs is still inadequate.

\subsubsection{Context of the Study}

The context of social influence is an important consideration as it can affect the study outcomes. For example, the theoretical perspective of social influence originated in the faceto-face, physical context of human interactions. However, we observed that this theory was employed by approximately $65 \%$ of studies that considered SNSs or virtual community as the context (denoted with an $\left(^{*}\right)$ for virtual community studies and $\left({ }^{* *}\right)$ for SNS studies in Table 4). In contrast with the studies employing other social interaction media, no study in our sample explicitly observed the theoretical challenges in employing the social influence theory in SNSs.

When considering the virtual community studies $\left(^{*}\right)$, Bagozzi and Dholakia (2002) examined how different social influence processes lead individuals to actively participate in virtual chat rooms. Song and Kim (2006) investigated the willingness of individuals to use virtual services based on social influence processes. While these two studies mainly focussed on how individuals would engage with a particular online service due to social influence, Miller and Brunner (2008) explored how different characteristics of individuals expressed through the digital sphere and their mere online presence would influence others to behave differently.

When SNS studies $\left(^{* *}\right)$ are considered, Zeng et al., (2009) examined how social identity and group norms affected "community users" group intentions to accept advertising in "online social networking communities" (Zeng et al., 2009, p. 1). Cheung and Lee (2010, p.24) investigated the role of compliance, identification, and internalization in "the decision to use an online social network". Such diverse use of social influence constructs in both virtual community and SNS studies indicates the necessity of rethinking the adaption of social influence constructs to the specific context of SNSs. In other words, due to the range of 
attitudinal and behavioural changes that take place within SNSs as a result of social influence, simply applying the same social influence constructs from pre SNS era may not be adequate to understand how social influence operates in SNSs. Further, while both virtual community and SNS studies have highlighted the importance of adopting selected constructs of social influence, such studies have rarely addressed the necessity of further refining the theoretical perspective of social influence to apply it successfully to the context of SNSs. This limitation encouraged us to look into boundary conditions that could allow IS researchers to streamline social influence for SNSs better.

Therefore, the next step of the analysis was to derive boundary conditions based on the study sample. We followed a logical approach to determine what boundary conditions would be suitable for SNSs when examining social influence. First, referring to selected seminal works on boundary conditions and theory building, we identified how boundary conditions could be utilized to better apply a theory to a particular context and yield accurate findings (Bacharach, 1989; Busse, Kach, \& Wagner, 2017; Dubin, 1969; Weber, 2012; Whetten, 1989). Then, we carefully reviewed the papers in the literature sample, through several iterations, to examine the recurring notions/themes in the literature sample that have been identified as useful when applying social influence to the context of SNSs. For instance, if several studies in the sample identified that the ability of SNS users to include or exclude people from their social circles (having a choice) should be considered when investigating social influence in SNSs, we looked at all the papers in the study sample, using that condition as a lens, to determine whether that condition could be applied to examine social influence in SNS related research more effectively. The conditions identified in this way were included as boundary conditions of social influence for SNSs. We continued this exercise, on identifying the conditions considered essential for studying social influence in SNSs across all 65 papers and derived five boundary conditions.

\section{Focus on Boundary Conditions}

The literature sample demonstrates that, while we have made substantial leaps in technology by creating SNSs, arriving at a hyper-connected society, our theoretical foundations employed in IS studies have barely changed. This notion has also been highlighted in a study on social network analysis and SNSs (Kane, Alavi, Labianca, \& Borgatti, 2014) which claims that researchers should not merely rely on theories developed prior to the advent of SNSs to understand the SNS related phenomena, since SNSs have changed the way social networks operate at present. Similarly, in our study, we argue that even though social influence processes would still be affected by the influencer's popularity, the influencer's relationship with the influencee, and the internal values of the influencee (Hovland et al., 1953) as in the pre SNS era, there are certain conditions (boundary conditions) facilitated by SNSs that make the social influence processes different to those operating in the traditional context.

In particular, only a limited number of studies in our literature sample pay attention to possible boundary conditions at least implicitly when applying a theoretical foundation that was derived based on face-to-face human influence to the context of augmented, inflated, and excessive social influence of SNSs. For instance, Venkatesh and Davis (2000) examined the concept of voluntariness as affecting compliance and highlighted that compliance would be effective only in situations where a particular action is mandatory. Yet, the study is not specific to the context of SNSs. However, Zhou (2011), when studying SNS user participation, 
indicated that compliance does not affect SNS user participation since participation is a voluntary decision made by the user. This factor is further discussed later in this study.

While consistency in employing the constructs of social influence would lead to a cumulative tradition of research, the lack of acknowledgment of a major shift in the context - face-to-face to virtual - not only weakens our observations, but it also precludes us from forming a precise understanding of the nature of social influence in the new context (Busse et al., 2017).

Hence, these gaps in the research could be addressed by revisiting boundary conditions and identifying which boundary conditions can be applied to the context of SNSs to analyze the actions that take place within this context. Even though various disciplines have studied the nature of social influence generated in SNSs among individuals, much of the theoretical work underpinning these discussions has been based on the theories that were developed prior to the advent of SNSs.

Herein we specifically propose that, when considering social influence, studies must specify and observe conditions that the constructs are bounded by (Dubin 1969). The boundary conditions are derived through a comparison of the conditions upon which the traditional social interactions (e.g., face-to-face) are based against the conditions upon which the digital interaction happens. These limiting values are particularly potent in the SNS context. Lack of boundary condition specificity in emerging research could lead to either type-I or type-II errors. For example, you may reject the true null hypothesis (type-I) or fail to reject a false null hypothesis (type-II), by inadvertently selecting a particular sample that may not be random.

In order to better illustrate this, we derived five salient boundary conditions through the analysis of our literature sample that affect the nature of social influence in the SNS era. These five factors can provide what Dubin called the boundaries of the theory. Dubin (1969, p.125), stated that "in order that a model may represent an empirical system, it has to have the boundaries corresponding to the empirical system. The boundaries are important to the specification of any theoretical model." The derived five boundary conditions; (i) the choice, (ii) space and proximity, (iii) the locus of social influence, (iv) the number of people and times, (v) the diversity and the variety of social influence, would thus add meaning to the future social influence studies in the context of SNSs.

\subsection{The Choice of the Social Circle}

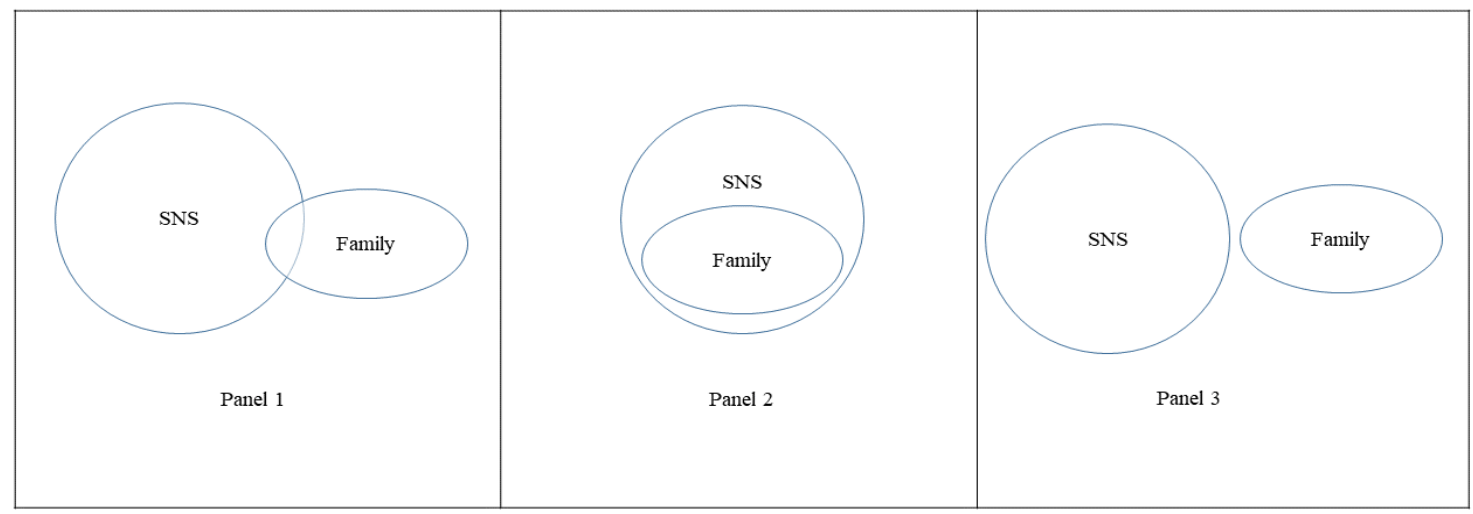

Figure 1. The Choice of the Social Circle 4

\footnotetext{
4 Figure 1 to Figure 5 have been inspired and adapted by Dubin's (1969) work on boundary conditions.
} 
Figure 1 outlines the choice condition, which is necessary for SNS studies. For instance, as illustrated in panel 1, some of your family members can be a part of your social circle in the SNSs, or as depicted in panel 2, all your family members can be members of your SNS social circle. Another condition that could be applicable for an individual in SNSs is illustrated in panel 3, when the individual decides to keep his/her family members away from the SNS's social circle. Thus, the individual has a choice when making decisions in SNSs or when adding or removing a person from the social circle of a SNS.

Bagozzi and Dholakia (2002) differentiated such conditions in virtual communities from the conditions in traditional communities, stating that members of SNSs have a voluntary association with the membership. Therein, the individual could quit the network at any given time without participation. Hall and Fagen (1956) described such boundary conditions as exterior boundary conditions. It is argued that when a new unit of measurement must be introduced into a theorem, the unit must be designated affirmatively, as must be the theorem (Dubin 1969). Hall and Fagen (1956) emphasized that in cases when an exterior boundary condition changes the outcome of a proposed model, such variables should be considered as intervening variables (moderation, mediation assumed). Therefore, in social influence studies, the choice one would exert in determining one's own social network should be considered.

Zhang et al. (2018) investigated the direct vs. indirect peer influence in social networks, arguing that "Peer influence can arise from immediate neighbors in the network and from indirect peers who share common neighbors (p. 1)". Their findings, based on an analysis of call logs, demonstrate significant differences between the direct and indirect influences. Given that in SNSs, individuals are exposed to a large number of direct and indirect peer influences at once, the choice of an individual in SNSs to exclude/include people from his/her social circles affects the influence they receive.

Identifying the most used constructs in the literature sample, such as normative social influence, compliance, and identification, further confirmed the necessity of considering the boundary condition choice of the social circle. In SNSs, individuals have to comply with diverse types of rules because the individual can belong to many groups. Zhou (2011) highlighted that since participation in SNSs is a voluntary choice a person makes; the opinions of others do not matter in decision making. In contrast, Cheung and Lee (2010) showed that compliance and identification determine a person's motive for using SNSs. Even though both Cheung and Lee (2010) and Zhou (2011) discussed only the user's participation in SNSs, these studies confirm the necessity of a boundary condition on choice for SNSs.

Therefore, for studies on social influence, the choice condition should be specified, as the social influence would only arise from those whom you have selected to be included in your SNS profile. For example, when constructs like (A) compliance, (B) identification, (C) internalization or (D) peer influence are considered, the choice that the individual has consciously made must be considered. Similarly, when measuring social impact through constructs like $(\mathrm{G})$ immediacy and $(\mathrm{H})$ strength, these constructs are be impacted by the choice condition. 


\subsection{Space and Proximity}

\begin{tabular}{cll|}
\hline $\mathbf{p}$ & \multicolumn{1}{c}{$\mathbf{q}$} & $\mathbf{p}^{\wedge} \mathbf{q}$ \\
\hline True & True & True \\
True & False & False \\
False & True & False \\
False & False & False \\
& & \\
\hline
\end{tabular}

Figure 2. Space and Proximity

Figure 2 outlines an example of a truth table for the proximity condition. We argue that both ' $\mathrm{p}$ ' and ' $\mathrm{q}$ ' must be understood in social influence studies, where ' $\mathrm{p}$ ' is the digital proximity, and ' $\mathrm{q}$ ' is the physical proximity that one has to a network or its subjects. By digital proximity, we mean the proximity between SNS users in terms of belonging to the same online group, or being members of the same SNS page, due to which the SNS users feel a form of connectedness. By physical proximity, we mean the proximity maintained due to one's geographical location. People belonging to the same region or area would be influenced by each other more. Latané and Bourgeois (1996) in their works on the Dynamic Social Impact theory ${ }^{5}$ highlighted that social influence, at least concerning memorable interactions, seems to decrease with the square of the distance. However, the same study suggests that with the influence of technology, the social space between people will be affected, and the effective distance between people reduced. Digital proximity is how this aspect is changed due to the influence of the technology, where people feel closer to each other in spite of their physical distance.

When applied to social influence in SNSs, the presence of both physical and digital proximity between an influencer and an influencee would mean social influence processes such as (C) internalization as investigated in Table 4, would become more optimal. Similarly, the proximity of influence must be considered in $(G)$ immediacy to recognize the physical and digital distances of the influencer. The consideration of a boundary condition on space and proximity allows us to examine how different social influence processes would become less or more optimal based on digital and physical proximities between influencers and influencees. Our literature analysis showed that one of the least used constructs in the study sample was immediacy, which indicates that researchers have underutilized constructs that could add more depth to our understanding of social influence in SNSs. However, there are SNS and digital space focused studies that have identified the application of proximity conditions in digital interactions (Miller \& Brunner, 2008; Singh \& Phelps, 2013; Wang et al., 2013). For instance, the study by Dewan et al. (2018), implicitly discusses the proximity condition. They acknowledge the difficulties in assessing proximity in SNSs, stating that "identifying proximity influence using observational data is challenging due to homophily, which may influence both the formation of social ties and music consumption decisions" (p. 119).

Furthermore, Miller \& Brunner (2008, p. 2977), in examining online social influence using the theory of social impact, discussed the immediacy construct in online communities as "a participant's proximity to the chat room dialogue as evidenced by a participant's number of

\footnotetext{
5 Dynamic social impact theory consists of four constructs, namely clustering, correlation, consolidation and continuing diversity. Latané and Bourgeois (1996) have utilized these 4 constructs to analyze user behaviors in electronic groups and thereby to explore the operation of social impact in social space.
} 
contributions and their total number of contributed words". Pempek, Yermolayeva, and Calvert (2009) indicated that college students maintain connections on SNSs, usually with people who have been known to them in the physical world. These previous works highlight how physical proximity can influence SNS users in their decisions and confirm the necessity of considering both digital proximity and physical proximity when engaging in social influence research in the context of SNSs.

\subsection{The Locus of Social Influence}

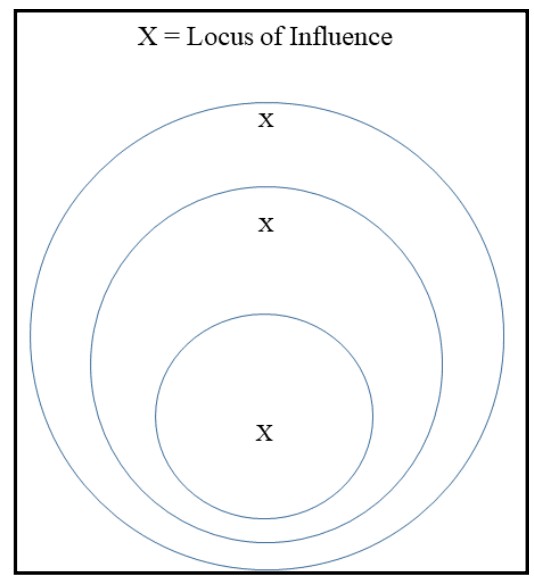

Figure 3. The Locus of Social Influence

Figure 3 denotes the locus of social influence. It recognizes that there are multiple realms of networks, not just one layer of social network around an individual. As such, social influence may arise from any of those realms. However, it is asserted that not all realms have the same level of social influence. Depending on the nature of the event and the nature of the influencer or the group affiliated, the individual could be receptive to the influencer. For example, the \#Metoo movement against sexual harassment had active participation from 85 countries (Park, 2017).

Furthermore, the locus of social influence would have an effect on studies employing the (C) internalization as an aspect of social influence. Given the realms of social networks, internalization may be short-term or long-lasting, depending on the locus of social influence. For instance, Tufekci and Wilson (2012), examining a political protest in Egypt, indicated how the political content generated by a few groups such as journalists, and activists, escalated to the level of a real-world protest due to the adoption and acceptance of the political ideology spread through SNSs by the general public. Particularly as depicted in Table 4, this study has implicitly identified social influence constructs such as (E) informational influence and $(\mathrm{H})$ strength to elaborate how individuals coming from various realms in SNSs motivated other individuals to take part in this political protest. As such, exploring the boundary condition of locus of social influence in future studies would enable us to explore social influence processes more precisely, considering the nature of the influencers in changing the attitudes and behaviors of other individuals using SNSs.

In addition, the ice bucket challenge can be considered as another good example that shows the applicability of the boundary condition of the locus of social influence. The Ice bucket challenge was first initiated by celebrities who are famous worldwide (Ni, Chan, Leung, Lau, \& Pang, 2014). As per Facebook (2014) "over 28 million people have joined the conversation about the ice bucket challenge including posting, commenting or liking a challenge post" and 
"2.4 million videos related to the ice bucket challenge have been shared on Facebook". This trend implicitly denotes the nature of social influence in SNSs. It also emphasizes how an initiative of celebrities could escalate into a mass sharing of videos by the SNS population that would motivate individuals to act based on the influence generated in various realms. Cheung, Chiu, and Lee (2011, p. 1340) stated that in SNSs, "if a user joins too many communities, it is hard for him/her to create a sense of belonging to a specific group". In such instances, the users may be confused in determining whether or not to engage in a certain action, as he/she could be receiving contradictory messages from multiple influencers. As such, the observations we made under the analysis of the literature sample denoted that further investigation of boundary conditions such as the locus of social influence is crucial in examining the social influence in complex platforms such as SNSs.

\subsection{The Number of People and Number of Times}

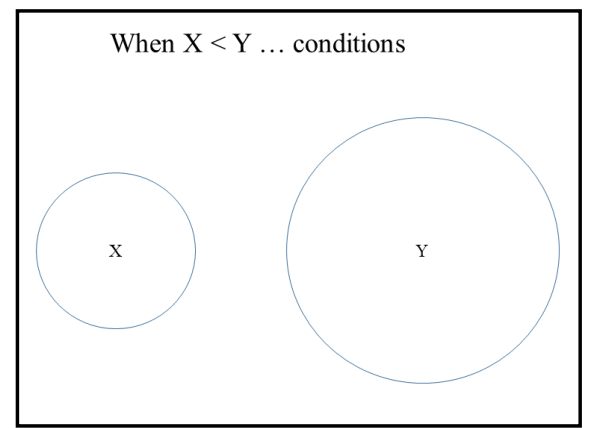

Figure 4. The number of People and Times

Figure 4 demonstrates the possible effect that the number of people and the number of times has on social influence constructs. Herein, we claim that the more people you are exposed to in SNSs, and the more times a particular message is circulated, the higher the tendency of a person to be influenced in the context of SNSs. For instance, Facebook indicates that individuals have an average of 338 friends (Smith, 2017). While the exact number may be debatable, it is evident that SNSs allow one to connect with more friends than pre SNS era (Mangold and Faulds 2009). When a statement or a post is cited by a high number of people in your network, it is likely to have a strong influence. The fundamental premise of repeated message (Black, 1949) is developed on the premise of the influence of the number and time premises. Thus, constructs like (E) informational social influence, and (F) normative social influence will be affected by the number of people and number of times. For instance, Kuan et al. (2014) in their study on online buying behaviors, highlighted that information on the number of people who have bought a product (informational social influence, and thereby the number of times and number of people) and the type of people who have liked a product (normative influence) in SNSs, affect the purchase decisions of consumers.

As illustrated in Table 4, the study of Kuan et al. (2014) has investigated many constructs of social influence such as (A) compliance, (B) identification, (D) peer influence, (E) informational social influence, (F) normative social influence, $(\mathrm{H})$ strength and (I) number of people, implicitly to examine the actions of consumers. Herein, the application of the boundary condition of the number of people and number of times would allow us to explore the power that lies in SNSs to spread social influence to a larger population due to the repetition of the same message by many influencers in SNSs. Furthermore, Kwahk \& Ge (2012, p.1817) in studying the impact of SNSs on e-commerce, state that "more social media interaction ties can bring higher group pressure and lead one to conform to the group" (number of people). This aspect also denotes the 
possibility of applying the boundary condition of the number of people and number of times to SNS research in examining social influence.

\subsection{The Diversity and the Variety of Social Influence}

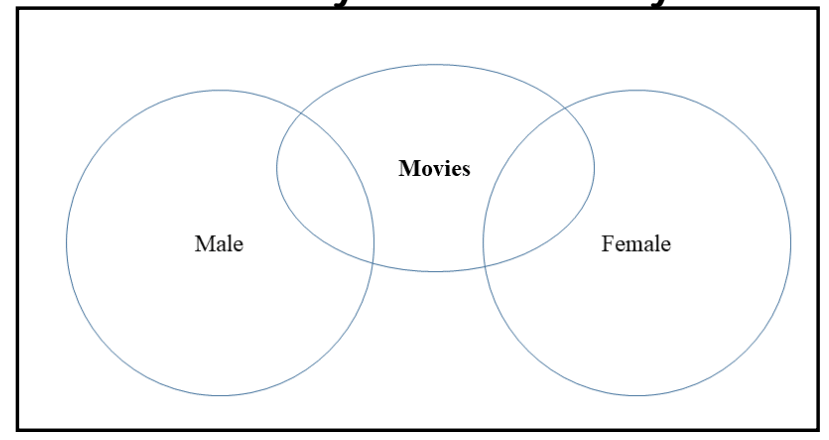

Figure 5. The Diversity and the Variety of Social Influence

Figure 5 recognizes the diversity and the variety of connections maintained in SNSs (Walther et al. 2008). As expressed in Figure 5, maleness plus movies has a narrower domain than either one alone. When comparing the diversity and the variety of social influence in traditional vs. SNSs, Kwahk and Ge (2012, p. 1816) indicated that in the past, social circles had narrower diversity, but with the proliferation of SNSs, social influence is getting "broader and stronger" making the presence of SNSs a critical aspect of peoples' lives. Shen, Lee, Cheung, and Chen (2010) explored how social influence and other related factors affect men and women differently when taking part in SNSs based team collaborations. Particularly when investigating multiple constructs of social influence in the context of SNSs such as (A) compliance, (B) identification, (D) peer influence, $(\mathrm{H})$ strength as depicted in Table 4, diversity and the variety of social influence allows us to examine the role of diverse influencers in SNSs in encouraging individuals to change attitudes or behaviors. The researcher has an obligation to specify which spectrum of social influence is sought based on the diversity and the variety of social influence a study population receives in SNSs.

In summary, the literature analysis conducted in the study indicates that applying social influence directly to SNSs and other digital spaces without considering these theoretical boundaries could lead to inconsistencies as well as ambiguities in the findings (Busse et al., 2017). As such, the above mentioned five boundary conditions, which we derived through several iterations of the literature review, would guide future research to apply social influence theoretical constructs to SNSs precisely and generate valid results relevant to the specific context of SNSs (Busse et al., 2017).

\section{Conclusion}

Social influence is an important stream of research that allows us to understand how the interactions among individuals in society lead to attitude and behavioral change. The existing theoretical foundations that investigate social influence, particularly in IS are under increasing pressure due to the advent and proliferation of SNSs. While much of the works on social influence have made substantial contributions to research, studies lack a nuanced view of the boundary conditions that are entrenched in SNSs. For instance, when utilizing the constructs generated by the social influence theories, previous studies have identified that not all constructs that generate social influence in the physical world can be applied in the same way to understand the social influence in SNSs (Datta, 2011; Shen, 2010; Zhou, 2011). By identifying 
this limitation in applying social influence on SNSs, this paper derived five boundary conditions based on a literature analysis and demonstrated how recognizing such boundary conditions up-front can provide better insights (Bacharach, 1989; Busse et al., 2017; Dubin, 1969; Gonzalez-Mulé \& Aguinis, 2018; Whetten, 1989).

Our analysis of the 65 past studies suggests that the boundary conditions are applicable to understand social influence in the contemporary setting of SNSs. The overlaps between the constructs of social influence, the acknowledgment in previous studies regarding the contextual differences between the society before and after the advent of SNSs, and the application of the five boundary conditions to constructs of social influence suggest the validity of this broader application.

Through this study, we make both theoretical and practical contributions to IS. Even though many IS studies have considered the theoretical perspective of social influence in examining individual attitude and behavioral changes, to date, no study has explicitly acknowledged the necessity of developing boundary conditions for SNS research. As such, the findings of this study can be utilized to investigate social influence in SNSs further. The identification of the five boundary conditions means that researchers can now develop instruments and procedures to measure these conditions (Busse et al. 2017; Dubin, 1969; Weber, 2012). Therefore, in terms of knowledge generation, we believe the findings of this study will serve as a lens in the domain of IS, allowing us to look at social influence generated by SNSs from a new perspective. Furthermore, seminal works on theory development have highlighted the contribution of boundary conditions in assisting researchers to generate valid findings (Busse et al., 2017; Dubin, 1969) and improving the generalizability of theories (Busse et al., 2017; Whetten, 1989). Similarly, by exploring five boundary conditions for social influence research in SNSs, we have identified that paying closer attention to boundary conditions when applying an existing theory to a new context would allow future studies to contribute to more rigorous research.

The derived boundary conditions would also enable future studies to be more specific when using social influence and make their findings more relevant to the context of SNSs. Further to this, practitioners will be able to develop strategies which can yield better outcomes with regard to their SNS campaigns. Notably, in terms of SNS marketing, the boundary conditions would allow practitioners to identify the optimal conditions for maximum social influence, and thus, encourage different behaviors among consumers. Moreover, we should also bear in mind that the exploration of boundary conditions has already been proven to reduce the gap between theory and practice (Busse et al., 2017). As such, whenever a researcher applies theory to any novel context including SNSs, determining the boundary conditions of the selected theory and examining whether or not the theory fits into the new contextual dimensions would not only facilitate the generation of accurate results but also ensure that the findings have practical implications.

However, one of the limitations we would like to acknowledge in this study is the formulation of boundary conditions based only on literature analysis. The five boundary conditions were determined based on literature, and the number of boundary conditions for SNSs social influence studies may vary depending on further empirical tests. For instance, conducting a social network analysis to examine the applicability of these boundary conditions would have been useful for the study. Nevertheless, our aim at this point is to highlight the necessity of developing boundary conditions for SNSs social influence studies, which we have 
accomplished through this study. Our study encourages future research to incorporate these boundary conditions for social influence in studies on SNSs so that the theoretical constructs of social influence can be applied in a novel way to relate to the context of SNSs. Further, the derivation of boundary conditions for the theoretical perspective of social influence can be improved if a comparative analysis of social influence theories could be conducted across different disciplines. Even though our findings reliant mainly on IS literature, included research findings from other disciplines including psychology, sociology, marketing, management studies, political science and communication studies, it was not within the scope of our study to conduct a comparative analysis of the use of social influence theoretical constructs for SNSs by placing equal emphasis on studies published in all disciplines.

\section{References}

Aral, S., \& Walker, D. (2011). Creating social contagion through viral product design: A randomized trial of peer influence in networks. Management Science, 57(9), 1623-1639.

Arvidsson, V., \& Holmström, J. (2013). Social media strategy: Understanding social media, IT strategy, and organizational responsiveness in times of crisis. Cutter IT Journal, 26(12), 18-23.

Bacharach, S. B. (1989). Organizational theories: Some criteria for evaluation. Academy of Management Review, 14(4), 496-515.

Bagozzi, R. P., \& Dholakia, U. M. (2002). Intentional social action in virtual communities. Journal of Interactive Marketing, 16(2), 2-21.

Bagozzi, R. P., Dholakia, U. M., \& Mookerjee, A. (2006). Individual and group bases of social influence in online environments. Media Psychology, 8(2), 95-126.

Bagozzi, R. P., Dholakia, U. M., \& Pearo, L. R. K. (2007). Antecedents and consequences of online Social Interactions. Media Psychology, 9(1), 77-114.

Bagozzi, R. P., \& Lee, K. H. (2002). Multiple routes for social influence: The role of compliance, internalization, and social identity. Social Psychology Quarterly, 65(3), 226-247.

Bapna, R., \& Umyarov, A. (2015). Do your online friends make you pay? A randomized field experiment on peer influence in online social networks. Management Science, 61(8), 19021920.

Black, J. W. (1949). The relation between message-type and vocal rate and intensity. Speech Monographs, 16(2), 217-220.

Boyd, D. M., \& Ellison, N. B. (2007). Social network sites: Definition, history, and scholarship. Journal of Computer-Mediated Communication, 13(1), 210-230. doi:10.1111/j.10836101.2007.00393.

Busse, C., Kach, A. P., \& Wagner, S. M. (2017). Boundary conditions: What they are, how to explore them, why we need them, and when to consider them. Organizational Research Methods, 20(4), 574-609.

Chaffey, D. (2020). Global Social Media Research Summary August 2020. Retrieved from https://www.smartinsights.com/social-media-marketing/social-media-strategy/newglobal-social-media-research/ 
Chan, K. H., Skoumpopoulou, D., \& Yu, Q. (2018). Firestorms on social media: Effects of social information characteristics on customer responses. Proceedings of the Twenty-Second Pacific Asia Conference on Information Systems. Yokohama, Japan. https://aisel.aisnet.org.

Chang, I. C., Liu, C. C., \& Chen, K. (2014). The push, pull and mooring effects in virtual migration for social networking sites. Information Systems Journal, 24(4), 323-346. doi:10.1111/isj.12030

Cheung, C. M., Chiu, P.Y., \& Lee, M. K. (2011). Online social networks: Why do students use Facebook? Computers in Human Behavior, 27(4), 1337-1343.

Cheung, C. M., \& Lee, M. K. (2010). A theoretical model of intentional social action in online social networks. Decision Support Systems, 49(1), 24-30.

Cialdini, R. B., \& Goldstein, N. J. (2004). Social influence: Compliance and conformity. Annual Review of Psychology, 55(1), 591-621.

Coleman, J. S. (1986). Social theory, social research, and a theory of action. American Journal of Sociology, 91(6), 1309-1335.

Datta, P. (2011). A preliminary study of ecommerce adoption in developing countries. Information Systems Journal, 21(1), 3-32.

Deutsch, M., \& Gerard, H. B. (1955). A study of normative and informational social influences upon individual judgment. The Journal of Abnormal and Social Psychology, 51(3), 629-636.

Dewan, S., Ho, Y.J., \& Ramaprasad, J. (2017). Popularity or proximity: Characterizing the nature of social influence in an online music community. Information Systems Research, 28(1), 117-136.

Dholakia, U. M., Bagozzi, R. P., \& Pearo, L. K. (2004). A social influence model of consumer participation in network- and small-group-based virtual communities. International Journal of Research in Marketing, 21(3), 241-263.

Dubin, R. (1969). Theory building. New York: Free Press.

Eckhardt, A., Laumer, S., \& Weitzel, T. (2009). Who influences whom? Analyzing workplace referents' social influence on IT adoption and non-adoption. Journal of Information Technology, 24(1), 11-24.

Facebook. (2014). The ice bucket challenge on Facebook. Retrieved from https: //newsroom.fb.com/news/2014/08/the-ice-bucket-challenge-on-facebook/

Fischer, E., \& Reuber, A. R. (2011). Social interaction via new social media: (How) can interactions on Twitter affect effectual thinking and behavior? Journal of Business Venturing, 26(1), 1-18.

Galaskiewicz, J., \& Wasserman, S. (1993). Social network analysis: Concepts, methodology, and directions for the 1990s. Sociological Methods E Research, 22(1), 3-22.

Garton, L., Haythornthwaite, C., \& Wellman, B. (1997). Studying online social networks. Journal of Computer-Mediated Communication, 3(1), JCMC313.

Godinho de Matos, M., Ferreira, P., \& Krackhardt, D. (2014). Peer influence in the diffusion of the iPhone 3G over a large social network. MIS Quarterly, 38(4), 1103-1133. 
Golder, S. A., \& Macy, M. W. (2014). Digital footprints: Opportunities and challenges for online social research. Annual Review of Sociology, 40(1), 129-152. doi:10.1146/annurev-soc071913-043145

Gonzalez-Mulé, E., \& Aguinis, H. (2018). Advancing theory by assessing boundary conditions with metaregression: A critical review and best-practice recommendations. Journal of Management, 44(6), 2246-2273.

Grottke, M., Hacker, J. V., \& Durst, C. (2018). Which factors determine our online social capital? An analysis based on structural equation modelling. Australasian Journal of Information Systems, 22. https://doi.org/10.3127/ajis.v22i0.1656

Hall, A. D., \& Fagen, R. E. (1956). Definition of system. General Systems, 1(1), 18-28.

Hovland, C. I., Janis, I. L., \& Kelley, H. H. (1953). Communication and persuasion; psychological studies of opinion change. New Haven: Yale University Press.

Kandel, E., \& Lazear, E. P. (1992). Peer pressure and partnerships. Journal of Political Economy, $100(4), 801-817$

Kane, G. C., Alavi, M., Labianca, G., \& Borgatti, S. P. (2014). What's different about social media networks? A framework and research agenda. MIS Quarterly, 38(1), 274-304.

Kaplan, A. M., \& Haenlein, M. (2010). Users of the world, unite! The challenges and opportunities of social media. Business Horizons, 53(1), 59-68.

Kelman, H. C. (1958). Compliance, identification, and internalization three processes of attitude change. Journal of Conflict Resolution, 2(1), 51-60.

Krippendorff, K. (1980). Content analysis: An introduction to its methodology. Beverly Hills, CA: Sage.

Kuan, K. K., Zhong, Y., \& Chau, P. Y. (2014). Informational and normative social influence in group-buying: Evidence from self-reported and EEG data. Journal of Management Information Systems, 30(4), 151-178.

Kwahk, K.Y., \& Ge, X. (2012). The effects of social media on e-commerce: A perspective of social impact theory. 45th Hawaii International Conference on System Sciences: IEEE, 18141823.

Latané, B. (1981). The psychology of social impact. American Psychologist, 36(4), 343-356.

Latané, B., \& Bourgeois, M. J. (1996). Experimental evidence for dynamic social impact: The emergence of subcultures in electronic groups. Journal of Communication, 46(4), 35-47.

MacCarthy, R. (2016). The average Twitter user now has 707 followers. Retrieved from https://kickfactory.com/blog/average-twitter-followers-updated-2016/

Mangold, W. G., \& Faulds, D. J. (2009). Social media: The new hybrid element of the promotion mix. Business Horizons, 52(4), 357-365.

McPherson, J. M., Popielarz, P. A., \& Drobnic, S. (1992). Social networks and organizational dynamics. American Sociological Review, 57(2), 153-170.

Miller, M. D., \& Brunner, C. C. (2008). Social impact in technologically-mediated communication: An examination of online influence. Computers in Human Behavior, 24(6), 2972-2991. 
Mir, I., \& Zaheer, A. (2012). Verification of social impact theory claims in social media context. Journal of Internet Banking and Commerce, 17(1), 1-15.

Morgan, K., Cheong, M., \& Bedingfield, S. (2018). “Power to the people!": Social media discourse on regional energy issues in Australia. Australasian Journal of Information Systems, 22. https://doi.org/10.3127/ajis.v22i0.1678

Nemeth, C. J. (1986). Differential contributions of majority and minority influence. Psychological Review, 93(1), 23-32.

Ni, M. Y., Chan, B. H., Leung, G. M., Lau, E. H., \& Pang, H. (2014). Transmissibility of the ice bucket challenge among globally influential celebrities: Retrospective cohort study. BMJ, 349 , g7185.

Oh, C., Roumani, Y., Nwankpa, J. K., \& Hu, H.F. (2017). Beyond likes and tweets: Consumer engagement behavior and movie box office in social media. Information $\mathcal{E}$ Management, 54(1), 25-37.

Palekar, S., Atapattu, M. R., Sedera, D., \& Lokuge, S. (2018). Exploring spiral of silence in digital social networking spaces. Paper presented at the International Conference on Information Systems (ICIS 2015): Exploring the Information Frontier.

Palekar, S., \& Sedera, D. (2018). Influence of social broadcasting networks on news consumption. Australasian Journal of Information Systems, 22. https://doi.org/10.3127/ajis.v22i0.1707

Park, A. (2017). \#Metoo reaches 85 countries with $1.7 \mathrm{~m}$ tweets. Retrieved from https://www.cbsnews.com/news/metoo-reaches-85-countries-with-1-7-million-tweets/

Pempek, T. A., Yermolayeva, Y. A., \& Calvert, S. L. (2009). College students' social networking experiences on Facebook, Journal of Applied Developmental Psychology, 30(3), 227-238.

PlumX Metrics - Plum analytics. (n.d.). Retrieved from https://plumanalytics.com/learn/aboutmetrics/

Sedera, D., Lokuge, S., Atapattu, M., \& Gretzel, U. (2017). Likes - the key to my happiness: The moderating effect of social influence on travel experience. Information $\mathcal{E}$ Management, $54(6), 825-836$.

Shen, A. X. L., Lee, M. K. O., Cheung, C. M. K., \& Chen, H. (2010). Gender differences in intentional social action: We-intention to engage in social network-facilitated team collaboration. Journal of Information Technology, 25(2), 152-169.

Singh, P. V., \& Phelps, C. (2013). Networks, social influence, and the choice among competing innovations: Insights from open source software licenses. Information Systems Research, 24(3), 539-560. doi:10.1287/isre.1120.0449

Smith, A. (2014). What people like and dislike about Facebook. Retrieved from http://www.pewresearch.org/fact-tank/2014/02/03/what-people-like-dislike-aboutfacebook/

Smith, K. (2017). Marketing: 47 incredible Facebook statistics. Retrieved from https://www.brandwatch.com/blog/47-facebook-statistics/

Song, J., \& Kim, Y. J. (2006). Social influence process in the acceptance of a virtual community service. Information Systems Frontiers, 8(3), 241-252. 
Tsai, H.T., \& Bagozzi, R. P. (2014). Contribution behavior in virtual communities: Cognitive, emotional, and social influences. MIS Quarterly, 38(1),143-163.

Tufekci, Z., \& Wilson, C. (2012). Social media and the decision to participate in political protest: Observations from Tahrir square. Journal of Communication, 62(2), 363-379.

Vannoy, S. A., \& Palvia, P. (2010). The social influence model of technology adoption. Communications of the ACM, 53(6), 149-153.

Venkatesh, V., \& Davis, F. D. (2000). A Theoretical extension of the technology acceptance model: Four longitudinal field studies. Management Science, 46(2), 186-204.

Walther, J. B., Van Der Heide, B., Kim, S. Y., Westerman, D., \& Tong, S. T. (2008). The role of friends' appearance and behavior on evaluations of individuals on Facebook: Are we known by the company we keep? Human Communication Research, 34(1), 28-49.

Wang, Y., Alahakoon, D., \& De Silva, D. (2018). An extended cognitive situation model for capturing subjective dynamics of events from social media. Australasian Journal of Information Systems, 22. https://doi.org/10.3127/ajis.v22i0.1701

Wang, Y., Meister, D. B., \& Gray, P. H. (2013). Social influence and knowledge management systems use: Evidence from panel data. MIS Quarterly, 37(1), 299-313.

Wang, Y.Y., Susarla, A., \& Sambamurthy, V. (2015). The untold story of social media on offline sales: The impact of Facebook in the US automobile industry. International Conference on Information Systems. Fort Worth, Texas, USA.

Weber, R. (2012). Evaluating and developing theories in the information systems discipline. Journal of the Association for Information Systems, 13(1), 1-30.

Webster, J., \& Watson, R. T. (2002). Analyzing the past to prepare for the future: Writing a literature review. MIS Quarterly, 26(2), xiii-xxiii.

Whetten, D. A. (1989). What constitutes a theoretical contribution? Academy of Management Review, 14(4), 490-495.

Whiteside, N., Aleti, T., Pallant, J., \& Zeleznikow, J. (2018). Helpful or harmful? Exploring the impact of social media usage on intimate relationships. Australasian Journal of Information Systems, 22. https://doi.org/10.3127/ajis.v22i0.1653

Zeng, F., Huang, L., \& Dou, W. (2009). Social factors in user perceptions and responses to advertising in online social networking communities. Journal of Interactive Advertising, 10(1), 1-13.

Zhang, J., \& Centola, D. (2019). Social networks and health: New developments in diffusion, online and offline. Annual Review of Sociology, 45(1), 91-109. doi:10.1146/annurev-soc073117-041421

Zhang, K., Lee, M. K., \& Zhao, S. J. (2010). Understanding the informational social influence of online review platforms. Proceedings of the International Conference on Information Systems. St. Louis, Missouri, USA. https://aisel.aisnet.org.

Zhang, B., Pavlou, P. A., \& Krishnan, R. (2018). On direct vs. indirect peer influence in large social networks. Information Systems Research, 29(2), 292-314. 
Zhang, B., Susarla, A., \& Krishnan, R. (2014). A Bayesian model to predict content creation with two-sided peer influence in content platforms. Retrieved from http://dx.doi.org/10.2139/ssrn.2554689.

Zhao, K., Stylianou, A. C., \& Zheng, Y. (2018). Sources and impacts of social influence from online anonymous user reviews. Information $\mathcal{E}$ Management, 55(1), 16-30.

Zhou, T. (2011). Understanding online community user participation: A social influence perspective. Internet Research, 21(1), 67-81.

\section{Appendix A - List of References for the Literature Synthesis Table (Table 4)}

Algesheimer, R., Dholakia, U. M., \& Herrmann, A. (2005). The social influence of brand community: Evidence from European car clubs. Journal of Marketing, 69(3), 19-34.

Bagozzi, R. P., \& Dholakia, U. M. (2002). Intentional social action in virtual communities. Journal of Interactive Marketing, 16(2), 2-21.

Bagozzi, R. P., Dholakia, U. M., \& Mookerjee, A. (2006). Individual and group bases of social influence in online environments. Media Psychology, 8(2), 95-126.

Bagozzi, R. P., Dholakia, U. M., \& Pearo, L. R. K. (2007). Antecedents and consequences of online social interactions. Media Psychology, 9(1), 77-114.

Brandt, T., Bendler, J., \& Neumann, D. (2017). Social media analytics and value creation in urban smart tourism ecosystems. Information \& Management, 54(6), 703-713.

Cheung, C. M., Chiu, P.Y., \& Lee, M. K. (2011). Online social networks: Why do students use Facebook? Computers in Human Behavior, 27(4), 1337-1343.

Cheung, C. M., \& Lee, M. K. (2010). A theoretical model of intentional social action in online social networks. Decision Support Systems, 49(1), 24-30.

Datta, P. (2011). A preliminary study of ecommerce adoption in developing countries. Information Systems Journal, 21(1), 3-32.

Dewan, S., Ho, Y. J., \& Ramaprasad, J. (2017). Popularity or proximity: Characterizing the nature of social influence in an online music community. Information Systems Research, 28(1), 117-136.

Dholakia, U. M., Bagozzi, R. P., \& Pearo, L. K. (2004). A social influence model of consumer participation in network- and small-group-based virtual communities. International Journal of Research in Marketing, 21(3), 241-263.

Dholakia, U. M., \& Talukdar, D. (2004). How social influence affects consumption trends in emerging markets: An empirical investigation of the consumption convergence hypothesis. Psychology \& Marketing, 21(10), 775-797.

Eckhardt, A., Laumer, S., \& Weitzel, T. (2009). Who influences whom? Analyzing workplace referents' social influence on IT adoption and non-adoption. Journal of Information Technology, 24(1), 11-24.

Fischer, E., \& Reuber, A. R. (2011). Social interaction via new social media: (How) can interactions on twitter affect effectual thinking and behavior? Journal of Business Venturing, 26(1), 1-18. 
Gallivan, M. J., Spitler, V. K., \& Koufaris, M. (2005). Does information technology training really matter? A social information processing analysis of coworkers' influence on IT usage in the workplace. Journal of Management Information Systems, 22(1), 153-192.

Gensler, S., Völckner, F., Liu-Thompkins, Y., \& Wiertz, C. (2013). Managing brands in the social media environment. Journal of Interactive Marketing, 27(4), 242-256.

Glass, R., \& Li, S. (2010). Social influence and instant messaging adoption. Journal of Computer Information Systems, 51(2), 24-30.

Godinho de Matos, M., Ferreira, P., \& Krackhardt, D. (2014). Peer influence in the diffusion of the iPhone 3G over a large social network. MIS Quarterly, 38(4), 1103-1134.

Hanna, R., Rohm, A., \& Crittenden, V. L. (2011). We're all connected: The power of the social media ecosystem. Business Horizons, 54(3), 265-273.

Hildebrand, C., Häubl, G., Herrmann, A., \& Landwehr, J. R. (2013). When social media can be bad for you: Community feedback stifles consumer creativity and reduces satisfaction with self-designed products. Information Systems Research, 24(1), 14-29.

Hu, T., Kettinger, W. J., \& Poston, R. S. (2015). The effect of online social value on satisfaction and continued use of social media. European Journal of Information Systems, 24(4), 391410 .

Huffaker, D. (2010). Dimensions of leadership and social influence in online communities. Human Communication Research, 36(4), 593-617.

James, T. L., Wallace, L., Warkentin, M., Kim, B. C., \& Collignon, S. E. (2017). Exposing others' information on online social networks (OSN): Perceived shared risk, its determinants, and its influence on OSN privacy control use. Information \& Management, 54(7), 851865.

Kaplan, A. M., \& Haenlein, M. (2010). Users of the world, unite! The challenges and opportunities of social media. Business Horizons, 53(1), 59-68.

Kelman, H. C. (1958). Compliance, identification, and internalization three processes of attitude change. Journal of Conflict Resolution, 2(1), 51-60.

Kietzmann, J. H., Hermkens, K., McCarthy, I. P., \& Silvestre, B. S. (2011). Social media? Get serious! Understanding the functional building blocks of social media. Business Horizons, 54(3), 241-251.

Kuan, K. K., Zhong, Y., \& Chau, P. Y. (2014). Informational and normative social influence in group-buying: Evidence from self-reported and EEG data. Journal of Management Information Systems, 30(4), 151-178.

Kulviwat, S., Bruner II, G. C., \& Al-Shuridah, O. (2009). The role of social influence on adoption of high-tech innovations: The moderating effect of public/private consumption. Journal of Business Research, 62(7), 706-712.

Kwahk, K.Y., \& Ge, X. (2012). The effects of social media on e-commerce: A perspective of social impact theory. The 45th Hawaii International Conference on System Science (HICSS), 1814-1823.

Latané, B. (1981). The psychology of social impact. American Psychologist, 36(4), 343-356. 
Latané, B. (1996). Dynamic social impact: The creation of culture by communication. Journal of Communication, 46(4), 13-25.

Latané, B., \& Bourgeois, M. J. (1996). Experimental evidence for dynamic social impact: The emergence of subcultures in electronic groups. Journal of Communication, 46(4), 35-47.

Latané, B., Liu, J. H., Nowak, A., Bonevento, M., \& Zheng, L. (1995). Distance matters: Physical space and social impact. Personality and Social Psychology Bulletin, 21(8), 795-805.

Lee, Y., Lee, J., \& Lee, Z. (2006). Social influence on technology acceptance behavior: Selfidentity theory perspective. ACM SIGMIS Database: the DATABASE for Advances in Information Systems, 37(2-3), 60-75.

Li, X., Hess, T. J., \& Valacich, J. S. (2006). Using attitude and social influence to develop an extended trust model for information systems. ACM SIGMIS Database: the DATABASE for Advances in Information Systems, 37(2-3), 108-124.

Liao, C., Lin, H.N., Luo, M. M., \& Chea, S. (2017). Factors influencing online shoppers' repurchase intentions: The roles of satisfaction and regret. Information \& Management, 54(5), 651-668.

Lipsman, A., Mudd, G., Rich, M., \& Bruich, S. (2012). The power of "like": How brands reach (and influence) fans through social-media marketing. Journal of Advertising Research, 52(1), 40-52.

Lu, J., Yao, J. E., \& Yu, C.S. (2005). Personal innovativeness, social influences and adoption of wireless internet services via mobile technology. The Journal of Strategic Information Systems, 14(3), 245-268.

Mangold, W. G., \& Faulds, D. J. (2009). Social media: The new hybrid element of the promotion mix. Business Horizons, 52(4), 357-365.

Matook, S., Brown, S. A., \& Rolf, J. (2015). Forming an intention to act on recommendations given via online social networks. European Journal of Information Systems, 24(1), 76-92.

Miller, M. D., \& Brunner, C. C. (2008). Social impact in technologically-mediated communication: An examination of online influence. Computers in Human Behavior, 24(6), 2972-2991.

Mir, I., \& Zaheer, A. (2012). Verification of social impact theory claims in social media context. Journal of Internet Banking and Commerce, 17(1), 1-15.

Nowak, A., Szamrej, J., \& Latané, B. (1990). From private attitude to public opinion: A dynamic theory of social impact. Psychological Review, 97(3), 362-376.

Oh, C., Roumani, Y., Nwankpa, J. K., \& Hu, H. F. (2017). Beyond likes and tweets: Consumer engagement behavior and movie box office in social media. Information \& Management, 54(1), 25-37.

Pempek, T. A., Yermolayeva, Y. A., \& Calvert, S. L. (2009). College students' social networking experiences on Facebook. Journal of Applied Developmental Psychology, 30(3), 227-238.

Posey, C., Lowry, P. B., Roberts, T. L., \& Ellis, T. S. (2010). Proposing the online community self-disclosure model: The case of working professionals in France and the UK who use online communities. European Journal of Information Systems, 19(2), 181-195. 
Rueda, L., Benitez, J., \& Braojos, J. (2017). From traditional education technologies to student satisfaction in management education: A theory of the role of social media applications. Information \& Management, 54(8), 1059-1071.

Sedera, D., Lokuge, S., Atapattu, M., \& Gretzel, U. (2017). Likes - the key to my happiness: The moderating effect of social influence on travel experience. Information \& Management, 54(6), 825-836.

Shen, A. X., Cheung, C. M., Lee, M. K., \& Chen, H. (2011). How social influence affects weintention to use instant messaging: The moderating effect of usage experience. Information Systems Frontiers, 13(2), 157-169.

Shen, A. X. L., Lee, M. K. O., Cheung, C. M. K., \& Chen, H. (2010). Gender differences in intentional social action: We-intention to engage in social network-facilitated team collaboration. Journal of Information Technology, 25(2), 152-169.

Singh, P. V., \& Phelps, C. (2013). Networks, social influence, and the choice among competing innovations: Insights from open source software licenses. Information Systems Research, 24(3), 539-560.

Song, J., \& Kim, Y. J. (2006). Social influence process in the acceptance of a virtual community service. Information Systems Frontiers, 8(3), 241-252.

Thomaz, G. M., Biz, A. A., Bettoni, E. M., Mendes-Filho, L., \& Buhalis, D. (2017). Content mining framework in social media: A FIFA world cup 2014 case analysis. Information \& Management, 54(6), 786-801.

Tsai, H.T., \& Bagozzi, R. P. (2014). Contribution behavior in virtual communities: Cognitive, emotional, and social influences. MIS Quarterly, 38(1), 143-163.

Tufekci, Z., \& Wilson, C. (2012). Social media and the decision to participate in political protest: Observations from Tahrir square. Journal of Communication, 62(2), 363-379.

Tussyadiah, I. P., Kausar, D. R., \& Soesilo, P. K. (2015). The effect of engagement in online social network on susceptibility to influence. Journal of Hospitality \& Tourism Research, 42(2), 201-223.

Vannoy, S. A., \& Palvia, P. (2010). The social influence model of technology adoption. Communications of the ACM, 53(6), 149-153.

Venkatesh, V., \& Davis, F. D. (2000). A theoretical extension of the technology acceptance model: Four longitudinal field studies, Management Science, 46(2), 186-204.

Walther, J. B., Van Der Heide, B., Kim, S. Y., Westerman, D., \& Tong, S. T. (2008). The role of friends' appearance and behavior on evaluations of individuals on Facebook: Are we known by the company we keep? Human Communication Research, 34(1), 28-49.

Wang, Y.Y., Susarla, A., \& Sambamurthy, V. (2015). The untold story of social media on offline sales: The impact of Facebook in the US automobile industry. Thirty Sixth International Conference on Information Systems. Fort Worth, Texas, USA.

Wang, Y., Meister, D. B., \& Gray, P. H. (2013). Social influence and knowledge management systems use: Evidence from panel data. MIS Quarterly, 37(1), 299-313. 
Yang, H.D., Moon, Y. J., \& Rowley, C. (2009). Social influence on knowledge worker's adoption of innovative information technology. Journal of Computer Information Systems, 50(1), 25-36.

Zeng, F., Huang, L., \& Dou, W. (2009). Social factors in user perceptions and responses to advertising in online social networking communities. Journal of Interactive Advertising, 10(1), 1-13.

Zhang, B., Pavlou, P. A., \& Krishnan, R. (2018). On direct vs. indirect peer influence in large social networks. Information Systems Research, 29(2), 1-23.

Zhang, B., Susarla, A., \& Krishnan, R. (2014). A Bayesian model to predict content creation with two-sided peer influence in content platforms. Retrieved from http://dx.doi.org/10.2139/ssrn.2554689.

Zhou, T. (2011). Understanding online community user participation: A social influence perspective. Internet Research, 21(1), 67-81.

Copyright: () 2021 authors. This is an open-access article distributed under the terms of the Creative Commons Attribution-NonCommercial 3.0 Australia License, which permits noncommercial use, distribution, and reproduction in any medium, provided the original author and AJIS are credited.

doi: https://doi.org/10.3127/ajis.v25i0.2233

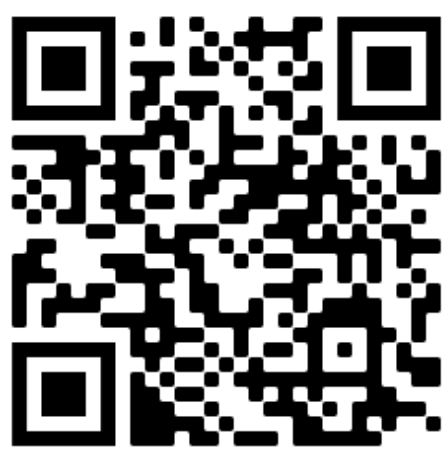

